EUROPEAN UNIVERSITY INSTITUTE DEPARTMENT OF ECONOMICS

\author{
EUI Working Paper ECO No. 2002/9 \\ Estimating Potential Output \\ and the Output Gap for the Euro Area: \\ a Model-Based Production Function Approach
}

Tommaso Proietti,

Alberto Musso and Thomas Westermann

BADIA FIESOLANA, SAN DOMENICO (FI) 
All rights reserved.

No part of this paper may be reproduced in any form without permission of the author(s).

(C) 2002 Tommaso Proietti, Alberto Musso and Thomas Westermann Published in Italy in May 2002

European University Institute

Badia Fiesolana

I-50016 San Domenico (FI)

Italy 


\title{
Estimating Potential Output and the Output Gap for the Euro Area: a Model-Based Production Function Approach
}

\author{
Tommaso Proietti, Alberto Musso `and Thomas Westermann $\ddagger$
}

\begin{abstract}
This paper evaluates unobserved components models based production function approach (PFA) for estimating the output gap and potential output for the Euro Area. Our main purpose is that of implementing in a consistent model based framework one of the most popular approaches to estimating those key macroeconomic latent variables, thereby avoiding the use of ad hoc signal extraction filters. We fit and validate, against a bivariate model of output and inflation, a system of five time series equations for the Solow's residual, labour force participation, the employment rate, capacity utilisation and the consumer price index; the first four equations are used to define the output gap, whereas the price equation relates the latter to underlying inflation, according to a triangle model. Several hypothesis of interest are entertained: the common cycle hypothesis, with capacity utilisation as the driving force, the hysteresis hypothesis, and we propose a model with pseudo-integrated cycles that is quite effective in eliciting cyclical information from the labour market variables, and enhances smoothness in potential output growth estimates. A rolling forecasts experiment is used to assess the out of sample predictive accuracy of the alternative models. The conclusion is that, although the PFA models cannot outperform a bivariate model of output and inflation, they can be valuable for growth accounting and for reducing the uncertainty surrounding the output gap estimates. We end with a discussion about the use of unobserved components methods to obtain a thorough assessment of the reliability of the output gap estimates.
\end{abstract}

Keywords: Common Cycles, Unobserved Components, Phillips Curve, Hysteresis, Smoothing, Inflation Forecasts, Reliability

*University of Udine and European University Institute. Address for correspondence: Department of Economics, European University Institute - Badia Fiesolana. Via dei Roccettini 9, San Domenico di Fiesole (FI) I-50016. Email: tproiett@iue.it

${ }^{\dagger}$ European University Institute and Euro Area Macroeconomic Developments, European Central Bank, Frankfurt am Main. The views expressed in this paper do not necessarily reflect those of the ECB

${ }_{\ddagger}^{\ddagger}$ Euro Area Macroeconomic Developments, European Central Bank, Frankfurt am Main. The same caveats apply. 


\section{Introduction}

Potential output, the associated output gap and the natural rate of unemployment are all concepts which have received increased attention over the past few years, within both central banks and international organisations as well as among academics.

Interest in these concepts, albeit with varying intensity, has been alive among analysts for several years now, the reason being that they are central to some of the main approaches to the formulation, analysis and assessment of monetary and fiscal policy. First, within a monetary policy framework, the output gap (defined as percentage deviations of output from potential) and the unemployment gap (i.e. deviations of unemployment from its natural rate) have often played a central role as indicators of inflationary pressures and therefore have been among the main building blocks of inflation forecasting models. The recent literature on monetary policy rules, aimed initially at providing a simple description of the monetary policy decision process of central banks, has also refocused attention to the output gap from a normative point of view (see Taylor, 1999). Second, from a fiscal policy perspective, the output gap represents a measure of the cyclical impact of developments on the public finances and is therefore instrumental in estimating structural budget deficits, which are needed to assess the sustainability of public debt. As a result, in the short run the output and unemployment gaps provide indications of the existence of either excessive demand or excessive supply, suggesting the most appropriate stance of fiscal and monetary policies. Finally, in the medium-to-long run, estimates of potential output growth and the natural rate of unemployment represent the main measures of the sustainable growth path of production and employment, thus offering useful indications on the appropriateness of economic policy strategies as well as on the need for structural reforms in the products and labour markets.

In the European context these concepts are particularly relevant for both monetary and fiscal policy. Within the framework of the monetary policy strategy of the European Central Bank (ECB), estimates of euro area potential output growth are an essential component in the derivation of the reference value for monetary growth (see Issing et al. 2001). Furthermore, measures of the output gap are used, together with several other indicators, for the purpose of estimating inflationary pressures in the context of the second pillar of monetary policy, and as an input in the forecasting models. Moreover, the Stability and Growth Pact assigns an important role to medium term structural budget balances, thus establishing the need to estimate cyclically adjusted budget deficits. Finally, given the decreasing but still relatively high levels of unemployment rates in most European countries, estimates of the structural unemployment rate indicate to what extent structural reforms in the labour markets are needed.

The two recent strands of literature on the uncertainty of output gap and natural rate of unemployment estimates ${ }^{1}$ have shown that the practical usefulness of these measures should not be overemphasised, as the bands of uncertainty of estimates tend to be large and real-time estimates, which are precisely the most important ones for policy purposes, are particularly less reliable. These problems can have severe negative consequences, as

\footnotetext{
${ }^{1}$ The literature has been largely influenced by the contributions of Orphanides and van Norden (1999) and Staiger et al. (1997). See also Ehrmann and Smets (2001) and Camba-Mendez and Rodriguez-Palenzuela (2001).
} 
wrong estimates can lead to wrong policy recommendations, as occurred in the seventies 2 . However, the last decade has witnessed significant improvements in measurement methods, which now allow the degree of uncertainty of estimates to be more precisely quantified and, especially, to reduced it. A notable example is represented by the refinement of modelling, estimation and inference of structural, or unobserved components, time series models, starting from Harvey (1989) and proceeding to Durbin and Koopman (2001).

The purpose of this paper is to propose a model based approach to estimate potential output and output gap, based on an unobserved components method that can address many of the issues raised by the literature referenced above. In particular, an empirical model consisting of a system integrating the production function approach and a model for inflation is formulated. This approach has the advantages of being grounded in economic theory and formulated in a general and flexible econometric framework which allows for the specification of the model to be tested and for uncertainty bands to be estimated. As by-product of the procedures also the structural unemployment rate can be obtained, along with measures of underlying inflation.

The approach is applied to the Euro area and covers the sample period 1970.1 2001.4. The paper is structured as follows. Section 2 provides a discussion of the concepts under analysis and reviews the theoretical foundations of the empirical model. Section 3 reviews the existing empirical methods proposed so far, whereas section 4 outlines the measurement model at the basis the production function approach. The empirical part of the paper sets off with a brief illustration of the available data (section 5). Univariate structural time series models (section 6) and bivariate models (section 7) are adapted to the Euro area output and consumer price index to provide suitable benchmarks for later comparison. Various multivariate models implementing the production function approach are discussed and estimated in section 8 and their performance assessed in terms of predictive accuracy and the suitability of the resulting measures of potential output and the output gap. The role of unobserved components methods for assessing the reliability of the estimates is discussed in section 9. The final section summarises the conclusions that can be drawn from the whole analysis.

\section{Economic foundations}

\subsection{Definitions of potential output}

Various definitions of potential output have been proposed and used in the literature, depending on the objectives of the investigator. One of the most influential discussions of potential output was provided by Okun (1962). In his seminal contribution, he defined potential output as the maximum quantity of output the economy can produce under conditions of full employment, specifying that the "full employment goal must be understood as striving for maximum production without inflationary pressures" (p. 98). The latter qualification, often also equivalently framed in terms of a "sustainable" level of production, gave an economic content to his definition, differentiating it from a pure engineering concept of maximum production attainable with a given set of inputs. The latter concept, as observed by Tobin (1998), may have some relevance in particular periods such

${ }^{2}$ See Freedman (1989), Orphanides (2001), and Nelson and Nikolov (2001). 
as in wartime, but in peacetime periods it is Okun's concept more of relevance from a macroeconomic point of view.

Okun's definition is still the main reference concept for economic policy-makers, including central banks. Later refinements of the definition stressed alternative aspects of the above-mentioned qualification, ranging from the intensity of use of labour and capital (for example, in Artus, 1977) to the link with the labour market, and in particular with the natural rate of unemployment (such as Gordon, 1984), but they are broadly equivalent.

A recent strand of theoretical macroeconomic literature, based on the New Neoclassical Synthesis (also known as New Keynesian Dynamic Stochastic General Equilibrium) class of models, has also paid an increasing attention to the concept of the output gap (see for example Gali, 2002). However, contributions within this approach refer to a different concept of potential output, the equilibrium level reached without nominal rigidities, that is, with fully flexible prices and wages. As admitted by the same authors within this literature, their concept of potential output and the output gap have little resemblance with the concepts used in traditional analysis of monetary policy.

\subsection{The time-horizon: the medium run}

Economic policy requires different time horizons depending on the final objective and the available instruments. For example, as recently pointed out by Smets (2000), there are various reasons why monetary policy strategies should adopt a medium-term orientation. First, monetary policy measures affect the final objectives only with a time lag. Second, a fine-tuning approach aimed at stabilising the economy in the short-run is likely to result in volatile interest rates and macroeconomic fundamentals. More in general, it can be argued that a medium-run horizon can help preventing pro-cyclical, destabilising economic policies.

At the same time, a precise temporal definition of medium-run is not desirable, mainly because monetary policy affects the macroeconomy with variable lags. These lags are difficult to estimate and vary along several dimensions, ranging from the presence of one or more shocks which justify the policy measure, the mix of transmission mechanisms at work, and the extent to which markets anticipated the monetary policy measure.

In the medium-run, both aggregate demand and aggregate supply are relevant and it is essential to differentiate changes in output growth which are due mainly to the former, possibly inflationary but temporary, or the latter, likely to be permanent and non-inflationary. This distinction is fundamental in order to interpret the events of the 1970 s and early 1980s, as opposed to the 1960s and early $1970 \mathrm{~s}^{3}$, and is relevant as well within the recent debate on the causes of the thriving macroeconomic performance over the second half of the 1990s, giving rise to the hypothesis of the emergence of a New Economy in the US and other advanced economies (see, for example, Gordon, 1998).

\subsection{A basic framework: the accelerationist model}

The basic economic framework, which represents the economic foundation of empirical methods aimed at estimating potential output, is the so-called accelerationist model. This

\footnotetext{
${ }^{3}$ See for example the discussion in Layard et al. (1991, p.16-18).
} 
model is the result of several contributions, the most important ones being represented by Phillips (1958), Okun (1962), Friedman (1968) and Phelps (1968) (for a historical review see Espinosa-Vega and Russell, 1997).

Its main building blocks are the expectations-augmented Phillips curve, Okun's law and the natural rate of unemployment. In the background lies a model for the determination of potential output and the natural rate ${ }^{4}$. Layard et al. (1991) provide a derivation of these blocks, which can be a useful reference to clarify the assumptions underlying the accelerationist model. Here, we will only briefly review it and then mention various extensions which have been successively proposed.

Firms, operating under monopolistic competition, set prices as a mark-up on expected wages. The mark-up depends on the level of the unemployment rate and possibly on other variables, such as the changes in the inflation rate (capturing price surprises) and the capital-labour ratio (as a proxy for productivity). Wage setting is based on both insider and outsider considerations. Thus, wages are set as a mark-up on expected prices, with the mark-up depending on the same factors as for prices, plus other exogenous factors such as union power, unemployment benefits, mismatch, and so forth. It is assumed that expectations are formed assuming that inflation follows a random walk. The equilibrium level of unemployment, or NAIRU 5 , derived under the assumption that expectations are fulfilled, depends on the degree of price and wage stickyness, as well as exogenous supply factors. On the basis of these building blocks, a trade-off relationship between the changes in inflation and the deviations of unemployment from the NAIRU, known as Phillips curve, can be derived.

Hysteresis effects can be introduced by assuming that wages and prices are set also on the basis of the changes in the unemployment rate. Within this general framework it is also possible to define a short-run NAIRU, as the level of unemployment consistent with stable inflation during the current period. The short-run NAIRU is obtained as a weighted average of the long-run NAIRU and the current unemployment rate, such that the weight attached to the latter depends on the relative importance of the hysteresis effect. As a consequence, the short-run NAIRU can be expected to be significantly more volatile than the long-run one.

Okun's law relates potential output to the natural rate of unemployment. Thus, it allows to express the Phillips curve as a relationship between inflation and the output gap.

The model is completed by specifying a production function, which relates output to capital, labour and total factor productivity, and a demand equation, typically derived as the reduced form of a simple IS-LM model.

Recent extensions of the model relate to the wage-price dynamics (see for instance Blanchard and Katz, 1999), the specification of demand (see for example Rudebusch and Svensson, 1999), nonlinearities (as suggested, among others, by Akerlof et al, 1996, Eisner, 1997, and Fair, 2000) and the open economy (Greenslade et al., 2000).

\footnotetext{
"Solow (2001, p. 285) for example defined "Growth theory as the theory of the evolution of potential output".

${ }^{5}$ The NAIRU is commonly defined as the Non-Accelerating Inflation Rate of Unemployment, but it should be more correctly referred to as the non-changing inflation rate of unemployment. It should also be noted that some differences between the NAIRU, an empirical concept, and the natural rate of unemployment, as defined by Friedman (1968) as a pure theoretical concept, exist -see for example Tobin (1997). However, we follow the common approach of considering the former as the empirical counterpart of the latter.
} 


\section{A review of the main econometric approaches}

A first level of classification of the econometric approaches to the measurement of potential output and the associated concept of output gap distinguishes between univariate and multivariate approaches.

In a univariate framework the measurement problem reduces to the trend-cycle decomposition of an indicator of aggregate economic activity, such as Gross Domestic Product at constant prices. Letting $y_{t}$ denote such indicator (in logarithms), the issue is decomposing $y_{t}=\mathrm{PO}_{t}+\mathrm{OG}_{t}$, where potential output, $\mathrm{PO}_{t}$, is the expression of the long run behaviour of the series and $\mathrm{OG}_{t}$, denoting the output gap, is a stationary component, usually displaying cyclic features.

However, the domain of the two concepts goes well beyond that of trends and cycles in output, which renders their measurement intrinsically multivariate. The definitions of the output gap as an indicator of inflationary pressure, given in section 2, and of potential as the level of output consistent with stable inflation, make it clear that a rigorous measurement can be operated at least within a bivariate model of output and inflation, embodying a Phillips curve relationship.

Moreover, information on the output gap is contained in macroeconomic variables other than aggregate output, either because those variables provide alternative measures of the output gap, or because they are functionally related to it (the Okun's law providing one such example). For instance, when available, measures of capacity utilisation convey further information on $\mathrm{OG}_{t}$, even though they have a more partial nature (they refer to the manufacturing sector, rather than to the whole economy).

Another useful classification is according to the methodology used. A distinction can be operated between unobserved components and observed components methods.

Unobserved components (UC) models have been widely used in the estimation of potential output and the output gap: univariate approaches rely on the Harvey and Jaeger (1993) trend-cycle decomposition of output and on the Hodrick and Prescott (1997) filter, which has also a model based interpretation. An early example of a multivariate UC model is provided by Clark (1989), who estimated a bivariate model of U.S. real output and unemployment grounded on Okun's law. Kuttner (1994) proposed a method for estimating potential output and the output gap based on a bivariate model of U.S. real GDP and CPI inflation. Gerlach and Smets (1999) focussed also on a bivariate model of output and inflation, but the output gap generating equation takes the form of an aggregate demand equation featuring the lagged real interest rate as an explanatory variable. Apel and Jansson (1999) obtained system estimates of the NAIRU and potential output for the U.K, U.S. and Canada, based on an unobserved components model of output, inflation and unemployment rates. Scott (2000) estimates the output gap for New Zeland using a trivariate system of output, unemployment and productive capacity. Other multivariate approaches are based on extensions of the Hodrick and Prescott filter: Laxton and Tetlow (1992) extended the penalised least squares criterion upon which the HP filter is based, so as to incorporate important macroeconomic relationship that are expressions of the output gap, such as the Phillips curve and the Okun's law.

Observed components methods rely on the Beveridge and Nelson (1981) decomposition and on structural vector autoregressive (VAR) models. The multivariate Beveridge and Nelson decomposition has been used by Evans (1989) to estimate the potential and cyclical 
components of U.S. real GNP within a bivariate VAR model for the changes of GDP and unemployment rate. The same system was considered by Blanchard and Quah (1989), who proposed a permanent transitory decomposition based on the identification restriction that demand shock have no permanent effect on output. Astley and Yates (1999) use a structural VAR model to estimate the output gap within a five variable system for the U.K. economy composed of quarterly log changes of oil prices, retail prices, real GDP, unemployment rates and capacity utilisation rates. St-Amant and van Norden (1997) use the same approach for the Canadian economy.

\section{The production function approach}

The production function approach is among the most popular methods of measuring potential output among statistical agencies, being currently employed by the OECD (see Giorno et al., 1995), the IMF (De Masi, 1997) and the CBO (1995). It is also the recommended approach by the EU Economic Policy Committe $e^{6}$. Its rationale is to obtain potential output from the trend levels of its structural determinants, such as productivity and factor inputs. A technology is used to appropriately weight the components. Contextually and consistently with the definition of PO, a Phillips type of relationship between inflation and OG complements the measurement model.

The production function approach defines realised output $\left(Y_{t}\right)$ as a combination of actual factor inputs, usually labour and capital, and total factor productivity $\left(\mathrm{TFP}_{t}\right)$. Assuming for simplicity that technology has a Cobb-Douglas representation exhibiting constant returns to scale, the aggregate production function takes the form:

$$
Y_{t}=\operatorname{TFP}_{t}\left(L_{t} H_{t}\right)^{\alpha}\left(C_{t} K_{t}\right)^{1-\alpha},
$$

where $\alpha$ is the elasticity of output with respect to labour. Labour input is defined as total hours worked (employment, $L_{t}$, times hours worked per head, $H_{t}$ ), and capital input, measured by the capital stock $K_{t}$, as derived from a perpetual inventory method, adjusted for the degree of capacity utilisation, $C_{t}$, taking values in the interval $(0,1]$.

Total factor productivity is not directly observable and it is usually derived as the so-called Solow residual from a growth accounting framework. This derivation is conventionally based on the notion that under perfect competition $\alpha$ is coincident with the labour share of output, and it can be estimated by the empirical average labour share obtained from the national accounts ( 0.65 for the Euro Area).

Assuming that all inputs are at their potential, i.e. equilibrium, non-inflationary levels, potential output, $Y_{t}^{(p)}$, can be written as a weighted geometric average of potential factor inputs, characterised by the superscript $(p)$

$$
Y_{t}^{(p)}=\operatorname{TFP}_{t}^{(p)}\left(L_{t}^{(p)} H_{t}^{(p)}\right)^{\alpha}\left(C_{t}^{(p)} K_{t}^{(p)}\right)^{1-\alpha} .
$$

The contribution of capital is equal to $K_{t}$, since, at potential, capacity utilisation takes the value $C_{t}^{(p)}=1$ and $K_{t}^{(p)}=K_{t}$. Potential hours worked, $H_{t}^{(p)}$, denote average weekly

\footnotetext{
${ }^{6}$ See the EPC "Report on Potential Output and the Output Gap", Oct. 2001, available at the URL http://europa.eu.int/comm/economy_finance/epc/documents: "...the production function approach can provide a broad and consistent assessment of the economic outlook as well as of macroeconomic and structural policies. It highlights how the various factor inputs and technical progress contribute to potential growth."
} 
working hours plus, for instance, any structural component of overtime or of absences due to illness. Potential employment, $E_{t}^{(p)}$, can be decomposed into three determinants, as we shall see shortly.

The information requirements are often too stringent; for instance, hours worked and capacity utilisation might be unavailable, with the consequence that the available information is unable to disentangle $H_{t}$ and $C_{t}$ from $\mathrm{TFP}_{t}$; as a result, the Solow's residual will typically display more cyclical variability than the latter.

The measurement model, however, can be restated in terms of the Solow's residual. Defining $F_{t}=\mathrm{TFP}_{t} H_{t}^{\alpha} C_{t}^{1-\alpha}$, taking the logarithms of both sides of (11) and denoting $y_{t}, l_{t}$ and $k_{t}$ respectively the logarithms of output, employment and capital stock, we can write:

$$
y_{t}=f_{t}+\alpha l_{t}+(1-\alpha) k_{t}
$$

Although in the sequel we will continue to refer to $f_{t}$ as total factor productivity, it must be recognised that $f_{t}=\ln F_{t}$.

All the variables on the right hand side of the equation 2 are decomposed additively into their potential and transitory components:

$$
f_{t}=f_{t}^{(P)}+f_{t}^{(T)}, \quad l_{t}=l_{t}^{(P)}+l_{t}^{(T)}, \quad k_{t}=k_{t}^{(P)} ;
$$

this breakdown enhances the extraction of information about the business cycle; in particular, $f_{t}$ is highly procyclical, whereas the capital stock contributes only to potential, being fully permanent ${ }^{7}$.

Employment has three determinants, as can be seen from the identity:

$$
l_{t}=n_{t}+p r_{t}+e_{t}
$$

where $n_{t}$ is the logarithm of total population, $p r_{t}$ is the logarithm of the labour force participation rate (LFPR), and $e_{t}$ is that of the employment rate. The determinants are in turn decomposed into their permanent and transitory components:

$$
n_{t}=n_{t}^{(P)}, \quad p r_{t}=p r_{t}^{(P)}+p r_{t}^{(T)}, \quad e_{t}=e_{t}^{(P)}+e_{t}^{(T)},
$$

and, accordingly, we obtain the permanent-transitory decomposition of $l_{t}$ :

$$
l_{t}^{(P)}=n_{t}+p r_{t}^{(P)}+e_{t}^{(P)}, \quad l_{t}^{(T)}=p r_{t}^{(T)}+e_{t}^{(T)} .
$$

The idea is that population dynamics are fully permanent, whereas labour force participation and employment are also cyclical. Moreover, since $e_{t}=\ln \left(1-U_{t}\right) \approx-u_{t}$, where $U_{t}$ is the unemployment rate and $u_{t}$ denotes its logarithms, we can relate the output gap to cyclical unemployment and potential output to structural unemployment.

\footnotetext{
7 This may be questionable, if one reflects on the statistical data generating process of the capital series. Given an initial estimate, $K_{0}$, the stock at time $t$ is obtained as $K_{t}=(1-\delta) K_{t-1}+I_{t}$ where $I_{t}$ denotes investments and $\delta$ is the depreciation rate; provided that the investment series is cyclical, the cycle in $K_{t}$ is a weighted infinite moving average the investment cycle with weights provided by $(1-(1-\delta) L)^{-1}$. This provides a simple example of a pseudo-integrated cycle, that we will introduce later in section 8.4 However, the current implementation of the perpetual inventory method adopted by statistical agencies differs from the stated formula in that the moving average is truncated at the average life of capital goods.
} 
Putting together the definitions (2)-(5) we achieve the required decomposition of output into potential and gap:

$$
\begin{aligned}
y_{t} & =\mathrm{PO}_{t}+\mathrm{OG}_{t} \\
\mathrm{PO}_{t} & =f_{t}^{(P)}+\alpha l_{t}^{(P)}+(1-\alpha) k_{t}^{(P)}, \\
\mathrm{OG}_{t} & =f_{t}^{(T)}+b l_{t}^{(T)},
\end{aligned}
$$

where e.g. potential output is the value corresponding to the trend values of factor inputs and $f_{t}$, whereas the output gap is a linear combination of the transitory values.

Finally, in agreement with the notion that potential output is the level of output that is consistent with stable inflation, the measurement model is augmented by a Phillips curve relationship. The latter relates the changes in the nominal price or wage inflation rate $\left(\Delta p_{t}\right)$ to an indicator of excess demand, typically the output gap $\left(\mathrm{OG}_{t}\right)$, and a set of exogenous supply shocks, such as changes in energy prices and terms of trade; a standard specification is the following:

$$
\phi(L) \Delta p_{t}=\theta(L) \mathrm{OG}_{t}+\sum_{k} \delta_{k}(L) x_{k t}+\epsilon_{\pi t}, \quad \epsilon_{\pi t} \sim \mathrm{WN}\left(0, \sigma_{\pi}\right),
$$

where $\theta(L)$ and $\delta_{k}(L), k=1, \ldots, K$, are polynomial in the lag operator $L, x_{t}$ denotes a set of exogenous supply shocks and $\phi(L)$ is an autoregressive (AR) polynomial.

There are three determinants of inflation in equation (7): inertia, taking the shape of autoregressive effects, demand, entering via the a lag polynomial of the output gap, and supply due to changes in energy prices and terms of trade. For this reason Gordon (1997) labels (7) as the triangle model. If the AR polynomial has a unit root, that is $\phi(1)=1$, then, if supply shocks are switched off, there exists a level of the output gap (here identified as zero) that is consistent with constant inflation.

Usually, the permanent levels of the variables contributing to PO and OG are estimated separately by a variety of ad-hoc filters, among which the HP filter (OECD), the splittrend method (IMF) or a segmented trend with break points occurring at peaks (CBO).

For instance, $f_{t}^{(P)}$ is estimated by the univariate HP filter applied to the series $y_{t}-\alpha l_{t}-$ $(1-\alpha) k_{t}$; transitory levels are obtained as a residual. See Giorno et al. (1995), de Masi (1997) and CBO (1995) for further details.

In this paper we adopt a system approach based on (2)-(6) and (7), according to which all the contributions are estimated simultaneously by a multivariate unobserved components model that incorporates the fundamental macroeconomic relationships among the variables.

Within the model based approach we can provide a more thorough assessment of the uncertainty surrounding the estimates of PO and OG, and address question such as the significance of the latter for inflation. These issues will be addressed in section 9 .

\section{Data and Overview}

The time series used in this paper are listed below (more information is provided in the Appendix): 


\begin{tabular}{lll} 
Series & Description & Transformation \\
\hline$y_{t}$ & Gross Domestic Product at constant prices & Log \\
$k_{t}$ & Capital Stock at constant prices & Log \\
$l_{t}$ & Employment, Total & Log \\
$f_{t}$ & Solow's residual $\left(y_{t}-0.65 l_{t}-0.35 k_{t}\right)$ & \\
$p r_{t}$ & Labour Force Participation Rate & $\log$ \\
CUR & Contribution of Unemployment Rate $\left(-e_{t}\right)$ & $\log$ \\
$n_{t}$ & Population & Log \\
$c_{t}$ & Capacity Utilisation (Survey based) & Log \\
$p_{t}:$ & Consumer prices index & Log \\
$\ln$ COMPR $_{t}:$ & Commodity prices index (both oil and non-oil) & Log \\
$\ln$ NEER $_{t}:$ & Nominal effective exchange rate of the Euro & Log \\
\hline
\end{tabular}

Quarterly observations are available for the period starting from the first quarter of the year 1970 and ending in the fourth quarter of 2001. All the series are non seasonal except for $p_{t}$ and $\ln \mathrm{COMPR}_{t}$; some weak seasonal effect was also detected for the labour market series, especially $\mathrm{CUR}_{t}$, as discussed below. A plot of the series is available in figure 1. The second panel shows that $f_{t}$ has a more pronounced cyclical behaviour with respect to $y_{t}$.

The contribution of the unemployment rate series $\left(\mathrm{CUR}_{t}\right)$ is defined as minus the logarithm of the employment rate. If $U_{t}$ denotes the unemployment rate, then $C U R_{t}=$ $-\ln \left(1-U_{t}\right) \approx U_{t}$ is the first order Taylor approximation of the unemployment rate. The approximation is quite good as can be seen overlaying the plots of $U_{t}$ and CUR $_{t}$ (the leading term of the approximation error is $-0.5 U_{t}^{2}$, and this is never greater than 0.007 ) and using the latter enables modelling the NAIRU without breaking the linearity of the model. The consequences for the measurement model amount only to a change of sign in (41) - (15).

The multivariate unobserved components models for the estimation of potential output and the output gap, based on the production function approach outlined in the previous section, are formulated in terms of the 5 variable system

$$
\mathcal{Y}_{t}=\left[\begin{array}{llll}
f_{t}, & p r_{t}, & \mathrm{CUR}_{t}, & c_{t}, \\
p_{t}
\end{array}\right]^{\prime}, \quad t=1, \ldots, T ;
$$

regression effects were included to account for intervention variables and exogenous variables, namely $\ln \mathrm{NEER}_{t}$ and $\ln \mathrm{COMPR}_{t}$ for the consumer prices equation. The information set up to time $t$ will be denoted by $\mathcal{F}_{t}$.

Unit roots and stationarity tests support the univariate characterisation of $y_{t}, f_{t}, p r_{t}$ and $\mathrm{CUR}_{t}$ as I(1) series; $p r_{t}$ and CUR $\mathrm{R}_{t}$ are subject to a downward level shift in the fourth quarter of 1992, consequent to a major revision in the definition of unemployment, which imposed more severe requirements for a person to be classified as unemployed (dealing in particular with the nature and the timing of job search actions), with the effect of enlarging the population not economically active, and thus bringing down participation and unemployment levels. To assess stationarity in the presence of a level shift in 1992.4 we referred to the Busetti and Harvey (2001) test, which lead to rejection of the null hypothesis.

The logarithm of capacity utilisation in the manufacturing sector is slightly trending; in particular, there is a downward movement at the beginning of the sample. As a matter of 
fact, the KPSS (see Kwiatowski et al., 1994) statistic testing against a RW with drift leads to reject the stationary hypothesis for any reasonable value of the truncation parameter of the nonparametric estimate of the long run variance. However, the no drift statistic is not significant for low values of the truncation parameter. In line with this evidence, the ADF test with a constant and a linear trend never rejects the unit root hypothesis, but when only a constant is included it leads to a clear rejection of the null. This motivated us to evaluate whether this dependence on the specification of the deterministic component could be due to a break in the trend. For this purpose, we performed the trend stationarity test unconditional on the location of the break proposed by Busetti and Harvey (2001); this clearly suggests that we cannot reject stationarity when the trend is linear and subject to a level shift and slope break occurring in 1975.1 (model 2b in the Busetti and Harvey paper). This is the data point that provided the most favourable evidence for the null of trend-stationarity when we allow for a break in the trend.

The series $p_{t}$ can be characterised as $\mathrm{I}(2)$; we addressed this issue by testing the stationarity of the quarterly inflation rate, $\Delta p_{t}$; since the series displays seasonality, we tested stationarity at the zero and the seasonal frequencies (annual and semiannual) using Canova and Hansen (CH, 1995) test (without including an autoregressive term), with a nonparametric correction for serial correlation. The statistic for stationarity at the zero frequency is highly significant, taking values no smaller than 0.997 (the $5 \%$ critical value is 0.461 ) for values of the truncation parameter between 0 and 10; if a linear trend is included we need a high value of the truncation parameter (7) to accept the null. As for seasonality, the $\mathrm{CH}$ statistics are never significant.

In the next sections we consider alternative estimates of PO and OG arising from univariate, bivariate and multivariate unobserved component models. The latter are modelbased implementations of the production function approach. Once the models are cast in the state space form the Kalman filter and the associated smoothing algorithms enable maximum likelihood estimation and signal extraction; for a thorough exposition of the state space methodology we refer to Harvey (1989) and Durbin and Koopman (2001). All the computations were performed using using the library of state space function SsfPack 2.3 by Koopman et al. (2000), linked to the object oriented matrix programming language Ox 3.0 of Doornik (2001), except for the univariate models dealt with in the next section, for which estimation was carried out in Stamp 6.2. (Koopman et al., 2000).

\section{Univariate estimates}

This section deals with univariate UC decompositions of the logarithm of the Euro area GDP into a trend component, $\mu_{t}$, a cyclical component, $\psi_{t}$ and additive noise, $\epsilon_{t}$, which are nested in the following model (see Harvey and Jäger, 1993):

$$
\begin{aligned}
y_{t} & =\mu_{t}+\psi_{t}+\epsilon_{t} & & \epsilon_{t} \sim \operatorname{NID}\left(0, \sigma_{\epsilon}^{2}\right), \\
\mu_{t} & =\mu_{t-1}+\beta_{t-1}+\eta_{t}, & & \eta_{t} \sim \operatorname{NID}\left(0, \sigma_{\eta}^{2}\right) \\
\beta_{t} & =\beta_{t-1}+\zeta_{t}, & & \zeta_{t} \sim \operatorname{NID}\left(0, \sigma_{\zeta}^{2}\right) \\
\psi_{t} & =\rho \cos \lambda_{c} \psi_{t-1}+\rho \sin \lambda_{c} \psi_{t-1}^{*}+\kappa_{t}, & & \kappa_{t} \sim \operatorname{NID}\left(0, \sigma_{\kappa}^{2}\right) \\
\psi_{t}^{*} & =-\rho \sin \lambda_{c} \psi_{t-1}+\rho \cos \lambda_{c} \psi_{t-1}^{*}+\kappa_{t}^{*}, & & \kappa_{t}^{*} \sim \operatorname{NID}\left(0, \sigma_{\kappa}^{2}\right)
\end{aligned}
$$


where $\eta_{t}, \zeta_{t}, \epsilon_{t}, \kappa_{t}$, and $\kappa_{t}^{*}$ are mutually independent. In the sequel we shall refer to $\mu_{t}$ as potential output, $\mathrm{PO}_{t}=\mu_{t}$, and to $\psi_{t}$ as the output gap, $\mathrm{OG}_{t}=\psi_{t}$, although in this single equation framework there is no guarantee that the latter is a measure of inflationary pressures.

The component $\mu_{t}$ is modelled as a local linear trend with an $\operatorname{IMA}(2,1)$ reduced form. For $\sigma_{\zeta}^{2}=0$ it reduces to a random walk with constant drift, whereas for $\sigma_{\eta}^{2}=0$ the trend is an integrated random walk (IRW). The reduced form of the cycle is the $\operatorname{ARMA}(2,1)$ process:

$$
\left(1-\phi_{1} L-\phi_{2} L^{2}\right) \psi_{t}=\left(1-\rho \cos \lambda_{c} L\right) \kappa_{t}+\rho \sin \lambda_{c} \kappa_{t-1}^{*},
$$

$\phi_{1}=2 \rho \cos \lambda_{c}, \phi_{2}=-\rho^{2}$. For $\lambda_{c} \in(0, \pi)$ the roots of the AR polynomial are a pair of complex conjugates with modulus $\rho^{-1}$ and phase $\lambda_{c}$; correspondingly, the spectral density displays a peak at $\lambda_{c}$, corresponding to a period of $2 \pi / \lambda_{c}$ quarters.

Model (8) was estimated unrestrictedly and also imposing restrictions on the variance parameters to enhance an I(1) trend, a smooth trend and the Hodrick and Prescott (1997, HP henceforth) trend. Parameter estimates are reported in table 1, along with the maximised log likelihood, the Ljung-Box statistics $Q(P)$ and the Doornik and Hansen (1994) normality test.

The unrestricted model (Model 1) estimates a short run cycle with a period of about three years, a damping factor close to 1, and with a very small disturbance variance; the smoothed estimates of $\psi_{t}$, presented in figure 2, show that the component is a poor representation of Euro Area business cycle. Also, underlying output growth (the smoothed estimate of $\Delta \mu_{t}$ ), displayed in the second panel, is highly volatile.

Model 2 restricts $\sigma_{\zeta}^{2}$ to zero; this representation is suggested by the stationarity of $\Delta y_{t}$, which is supported by the KPSS test. Naturally, nothing prevents that $\mu_{t}$ has richer dynamics than a pure random walk with a drift, and in the next section we consider a damped slope model according to which $\beta_{t}$ is a stationary first order autoregressive process and $\mu_{t}$ is $\operatorname{ARIMA}(1,1,1)$. As in the previous case, no variation is attributed to the irregular component, but the cyclical variability is much increased at the expenses of the trend (see fig. 2). Notice that the frequency of the cycle is virtually zero, and the estimated cycle has an $\mathrm{AR}(1)$ representation with parameter 0.91 . The changes in the trend fluctuate around a fixed mean with less variability than in the unrestricted case.

When a smoothness prior is imposed (Model 3, the trend is an IRW) a part of the total variability is absorbed by the irregular component, and the changes in the trend are fully represented by the slope component $\left(\Delta \mu_{t}=\beta_{t-1}\right)$ which evolves very smoothly over time. It would be a matter of an endless debate whether the resulting changes in potential output are overly "cyclical". The fluctuations may reflect different facts: an interaction of the trend and the cycle, or autonomous changes (one may ascribe the rise in underlying growth in the second half of the nineties to the "new economy"). Very little changes if one further restricts $\sigma_{\epsilon}^{2}=0$, apart from the fact that the cycle now absorbs the irregular movements.

The last column (Model 5) refers to the restricted version of (8) which yields the HP estimates of the trend. These amount to setting $\sigma_{\epsilon}^{2}=0, \rho=0$, so that $\psi_{t}=\kappa_{t} \sim$ $\operatorname{NID}\left(0, \sigma_{\kappa}^{2}\right), \sigma_{\eta}^{2}=0$, and $\sigma_{\zeta}^{2}=\sigma_{\kappa}^{2} / 1600$; hence, only the variance parameter $\sigma_{\kappa}^{2}$ is estimated (this parameter is concentrated out of the likelihood function). Both the relatively low value of the likelihood and the diagnostics strongly reject those restrictions. With respect 
to the previous two models (which also enforce a smoothness prior) the smoothed estimates of the irregular component, $\epsilon_{t}$, are characterised by more cyclical variability than those of $\psi_{t}$ and correspondingly, underlying growth is less variable.

As stated in section 3, univariate models provide a poor characterisation of the unobservable constructs we are deling with, and this makes us eager to pass promptly to the multivariate framework. The main purpose of this section was to illustrate the kind of model uncertainty that surrounds the estimation of PO and OG in the univariate framework. We will return to the uncertainty issue in section 9, Model selection and hypothesis testing constitute non standard issues and the reader is referred to Harvey (1989, ch. 5) and Harvey (2001) for these topics and for recent advances; however, for the reasons outlined above, we attach little relevance to the issue of selecting the best univariate model.

\section{A Bivariate Model of Output and Inflation}

A bivariate model of output and inflation combines equation (8), generating the output gap, $\mathrm{OG}_{t}=\psi_{t}$, and an equation relating inflation to it. We now discuss in some detail the structural specification of the equation for $p_{t}$. As the reduced form will show, it is a generalisation of the Gordon's triangle model of inflation accounting for the presence of possibly stochastic seasonality in the price series.

The equation is specified as follows:

$$
\begin{array}{rlrl}
p_{t} & =l_{t}+\gamma_{t}+\delta_{C}(L) \ln \mathrm{COMPR}_{t}+\delta_{N}(L) \ln \mathrm{NEER}_{t} & & \\
l_{t} & =l_{t-1}+\pi_{t-1}^{*}+\eta_{\pi t} & & \eta_{\pi t} \sim \operatorname{NID}\left(0, \sigma_{\eta \pi}^{2}\right), \\
\pi_{t}^{*} & =\pi_{t-1}^{*}+\theta_{\pi}(L) \mathrm{OG} t+\zeta_{\pi t} & & \zeta_{\pi t} \sim \operatorname{NID}\left(0, \sigma_{\zeta \pi}^{2}\right) ; \\
\gamma_{t} & =\gamma_{1 t}+\gamma_{2 t}, & & \\
\gamma_{1 t}=-\gamma_{1, t-2}+\omega_{1 t}, & \omega_{1 t} \sim \operatorname{NID}\left(0, \sigma_{\omega}^{2}\right), \\
\gamma_{2 t}=-\gamma_{2, t-1}+\omega_{2 t}, & \omega_{2 t} \sim \operatorname{NID}\left(0, \sigma_{\omega}^{2}\right) ;
\end{array}
$$

it is assumed that the disturbances are mutually independent and independent of any other disturbance in the output equation. Therefore, the only link between the prices and output equations is the presence of $\mathrm{OG}_{t}$ as a determinant of $\pi_{t}^{*}$.

According to (91) the logarithm of the consumer price index is decomposed into a seasonal effect, $\gamma_{t}$, an exogenous component driven by the nominal effective exchange rate of the Euro and commodity prices, and the unobserved component $l_{t}$, representing the underlying level of consumer prices devoid of any seasonal and exogenous effects; it evolves as a random walk with a slope component, $\pi_{t}^{*}$, that represents the underlying quarterly inflation rate. This is itself a nonstationary component whose evolution is driven by the output gap and a disturbance term $\zeta_{\pi t}$. Moreover,

- the exogenous variables enter the equation via the lag polynomials $\delta_{C}(L)=\delta_{C 0}+$ $\delta_{C 1} L$, and $\delta_{N}(L)=\delta_{N 0}+\delta_{N 1} L$. Note that $\delta_{C}(1)=\delta_{C 0}+\delta_{C 1}=0$ and $\delta_{N}(1)=$ $\delta_{N 0}+\delta_{N 1}=0$ imply long run neutrality of commodity prices and terms of trade, respectively, with respect to inflation.

- The unobserved component $\pi_{t}^{*}$ measures underlying inflation, and is very close to the notion of core inflation proposed by Quah and Vahey (1995) as that part of inflation 
that is driven by shocks that have no permanent impact on output. Apart from being characterised by inertia in the form of a unit root, it depends dynamically on the current and past values of the output gap, via the lag polynomial $\theta_{\pi}(L)=\theta_{\pi 0}+\theta_{\pi 1} L$. No further lags will be needed in our applications.

- $\gamma_{t}$ is a stochastic trigonometric seasonal component such that $S(L) \gamma_{t}=\theta_{s}(L) \omega_{t}^{*}$, $S(L)=1+L+L^{2}+L^{3}$, where $\theta_{s}(L)$ is an MA $(2)$ polynomial whose coefficient can be determined uniquely from the last three equations in (9); seasonality is deterministic when $\sigma_{\omega}^{2}=0$ in (9).

The reduced form of the equation (9) is:

$$
\begin{aligned}
\Delta \Delta_{4} p_{t}= & S(L) \theta_{\pi}(L) \mathrm{OG}_{t-1}+\delta_{C}(L) \Delta \Delta_{4} \ln \mathrm{COMPR}_{t}+ \\
& \delta_{N}(L) \Delta \Delta_{4} \ln \mathrm{NEER}_{t}+\theta(L) \epsilon_{t}
\end{aligned}
$$

where $\theta(L) \epsilon_{t}$ is the MA(4) reduced form representation of $S(L) \zeta_{\pi, t-1}+\Delta_{4} \eta_{\pi, t}+\Delta^{2} \theta_{s}(L) \omega_{t}$. Notice that the $S(L)$ filter applied to the contribution of the output gap avoids that the response of inflation to the output gap displays a seasonal feature. Hence the structural representation of Gordon's triangle model has the effect of isolating the response of the nonseasonal part of inflation with respect to the output gap.

When seasonality is deterministic (10) reduces to

$$
\begin{aligned}
\Delta^{2} p_{t}= & \theta_{\pi}(L) \mathrm{OG}_{t-1}+\mathrm{DS}_{t}+\delta_{C}(L) \Delta^{2} \ln \mathrm{COMPR}_{t}+ \\
& \delta_{N}(L) \Delta^{2} \ln \mathrm{NEER}_{t}+\theta(L) \epsilon_{t}
\end{aligned}
$$

where $\mathrm{DS}_{t}$ is a deterministic seasonal component and $\theta(L) \epsilon_{t}$ is the $\mathrm{MA}(1)$ representation of the process $\zeta_{\pi, t-1}+\Delta \eta_{\pi, t}$.

Gordon (1997) stresses the importance of entering more than one lag of the output gap in the triangle model, which allows to distinguish between level and change effects; this follows from the decomposition $\theta_{\pi}(L)=\theta_{\pi}(1)+\Delta \theta_{\pi}^{*}(L)$. In our case $\theta^{*}(L)=-\theta_{\pi 1}$; $\theta_{\pi}(1)=\theta_{\pi 0}+\theta_{\pi 1}=0$ implies that the OG has no permanent effect on inflation (but only transitory effects).

\subsection{Estimation results}

The unrestricted bivariate model (8)-(9) was estimated along with restricted version; these aim at investigating the sensitiveness of the results to different specifications of the trend in output and the leading or coincident nature of the output gap. The estimation results are reported in table 2. Complying with the evidence arising from the Canova and Hansen (1995) test the variance parameter of the seasonal component in (9) is always estimated equal to zero and seasonality is deterministic.

The unrestricted model produces a smooth potential output estimate that is very close to a deterministic trend: the estimated level disturbance variance is zero and the slope variance is very small. As a result the variance of the output gap is larger than that estimated by univariate models; its smoothed estimates are presented in figure 3 , The output gap makes a significant contribution to underlying inflation, as highlighted by the estimates of the coefficients of $\theta_{\pi}(L)$ and their standard errors. The null of long

run neutrality of $\mathrm{OG}_{t}$ on inflation is strongly rejected by the Wald test of the restriction 
$\theta_{\pi}(1)=0$, reported in table 2. However, the most relevant effect is the change effect, which takes the value 0.146; the level effect, about 0.02 , implies that if the output gap stays at $2 \%$ for two years (this would represent a major expansionary pattern) this would raise the inflation rate by 0.5 percentage points. Long run neutrality of $\ln \mathrm{NEER}_{t}$ and $\ln \mathrm{COMPR}_{t}$ is also rejected.

The second specification enforces the restriction that the trend is a RW with drift $\left(\sigma_{\zeta}^{2}=0\right.$ in equation (8) $)$. The trend, loosely speaking, absorbs now more variability and the output gap has lower amplitude. This is reflected in the higher estimates of the coefficients in $\theta_{\pi}(L)$.

We also considered a different specification of $\mathrm{PO}_{t}$ that is consistent with the $\mathrm{I}(1)$ hypothesis and allows the permanent component in output to display richer dynamics than a pure random walk with drift; this is Damped Slope model, according to which:

$$
\begin{aligned}
& \mu_{t}=\mu_{t-1}+m+\beta_{t-1} \\
& \beta_{t}=\phi \beta_{t-1}+\zeta_{t}, \quad \zeta_{t} \sim \operatorname{NID}\left(0, \sigma_{\zeta}^{2}\right)
\end{aligned}
$$

where $m$ is the constant drift and $\phi$ is the slope autoregressive parameter, taking values in $(-1,1)$. The resulting reduced form representation for $\mu_{t}$ is an $\operatorname{ARIMA}(1,1,1)$ process. This model provides the best fit to the data, and differs from the Unrestricted model in that $\mathrm{PO}$ growth is now evolving as an $\mathrm{AR}(1)$ process with $\mathrm{AR}$ coefficient equal to 0.84 .

The Coincident specification is model (8)-(9) estimated unrestrictedly, but with the contemporaneous rather than lagged value of underlying inflation entering the level equation, that is $l_{t}=l_{t-1}+\pi_{t}^{*}+\eta_{\pi t}$ (compare with (9)); this modification allows the reduced form model for $\Delta^{2} p_{t}$ to depend on $\theta_{\pi}(L) O G_{t}$, so that the output gap is a coincident, rather than leading, indicator of inflationary pressures. It seems difficult to discriminate this specification from the Unrestricted one solely on the basis of the estimation results presented in table 2, but the rolling forecast experiment of the next section will clearly point out that the Unrestricted model provides more accurate inflation forecasts.

Finally, we present the bivariate model with the HP restrictions $\left(\sigma_{\zeta}^{2}=1600 \sigma_{\epsilon}^{2}, \sigma_{\eta}^{2}=0\right)$ imposed on the stochastic formulation of the trend in output. Again, these restrictions are strongly rejected, as the residuals show very rich autocorrelation patterns.

It is perhaps useful to stress that all the specification extract a cycle with a very long period.

\subsection{Comparitive Performance of Rolling Forecasts for Bi- variate Models}

The five bivariate models can be now compared on the basis of their accuracy in forecasting inflation: if the output gap truly represents a measure of inflationary pressures, it must help in predicting future inflation. We use a rolling forecast experiment as an out-ofsample test of forecast accuracy. We assume that the variables to be forecasted are the annual inflation rate, $\Delta_{4} p_{t}$, and the quarterly rate, $\Delta p_{t}$, although we present results only for the former, as the conclusions are unchanged.

For this purpose the sample period is divided into a pre-forecast period, consisting of observations up to and including 1994.4. The 1995.1-2001.4 observations are used to evaluate and compare the out-of-sample forecast performance of the various alternative 
models. Hence, starting from 1995.1, each of the models of the previous section is estimated and 1 to 12 step-ahead forecasts are computed. Subsequently, the forecast origin is moved one step forward and the process is repeated until the end of sample is reached; the models is re-estimated each time the forecast origin is updated. The experiment provides in total 28 one step ahead forecasts and 16 three years ahead forecasts. Out-of-sample values for the exogenous variables were produced by the RW model for ln NEER and a local linear trend model (specified as in 8 , but with no cycle) fitted to the observations from 1985 onwards for ln COMPR.

We assess performance relative to the random walk model for quarterly inflation with seasonal drift (RWSD model and exogenous effects:

$$
\Delta^{2} p_{t}=\mathrm{DS}_{t}+\delta_{C}(L) \Delta^{2} \ln \mathrm{COMPR}_{t}+\delta_{N}(L) \Delta^{2} \ln \mathrm{NEER}_{t}+\xi_{t}, \quad \xi_{t} \sim \mathrm{NID}\left(0, \sigma^{2}\right) .
$$

which constitutes our benchmark. We also consider the univariate model (this is referred to as Univariate in this section) consisting of (9) without the output gap; this amounts to replacing $\xi_{t}$ by MA(1) errors, $\xi_{t}+\theta \xi_{t-1}$, with negative MA parameter, in (12).

The results, reported in table 3 indicate that there is an overall tendency is to slightly overpredict annual inflation, as indicated by the prevalence of negative mean forecast errors (expressed in percentage points). The largest biases correspond to the Coincident bivariate model. The mean square forecast errors, relative to the benchmark, clearly point out that the greatest forecast accuracy is provided by the Unrestricted bivariate model for forecast leads up to six quarters. For larger horizons, the bivariate models cannot outperform the Univariate forecasts.

The results also tell that the strategy of plugging the Hodrick and Prescott cycle estimates into the prices equation improves upon the Univariate model only at the one quarter lead time.

The bottom line reports the root mean square error for the benchmark model and points out that uncertainty is rather large: for instance, root mean square error of the forecasts of the annual inflation rate one year ahead arising from the the bivariate unrestricted model amounts to 2 percentage points ( $4 \%$ for the benchmark).

\section{Multivariate models implementing the Produc- tion Function Approach}

We consider multivariate unobserved components models for the estimation of potential output and the output gap, implementing the PFA approach outlined in section 4 that are formulated in terms of the 5 variables

$$
\left[f_{t}, \quad p r_{t}, \quad \mathrm{CUR}_{t}, \quad c_{t}, p_{t}\right]^{\prime}, \quad t=1, \ldots, T,
$$

including regression effects and intervention variables and exogenous variables, namely $\ln \mathrm{NEER}_{t}$ and $\ln \mathrm{COMPR}_{t}$ for the consumer prices equation. The latter has already been specified in (9), whereas for the permanent-transitory decomposition of the first four variables we use different models, that will be presented in separate sections.

We set off with an explorative approach, specifying a system of seemingly unrelated equations that is the multivariate analogue of (8), without assuming common cycles or 
trends (section 8.1). In section 8.2 we deal with a common cycle specification, with $c_{t}$ defining the reference cycle, and discuss within this framework the hysteresis hypothesis (section 8.3), according to which the cyclical variation affects permanently the trend in participation rates and unemployment. We finally introduce the pseudo-integrated cycle model, which provides an effective way of capturing the cyclical variability in the labour market variables. The models are compared in terms of goodness of fit and the ability to forecast annual inflation (section 8.5).

\subsection{Seemingly Unrelated Time Series Equations}

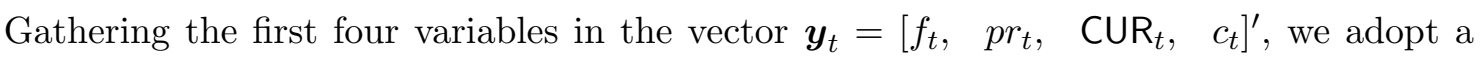
system of Seemingly Unrelated Time Series Equations (SUTSE) for estimating PO and OG according to the PFA. The system provides the multivariate generalisation of the decomposition (8), and is specified as follows:

$$
\begin{array}{rlrl}
\boldsymbol{y}_{t} & =\boldsymbol{\mu}_{t}+\boldsymbol{\psi}_{t}+\boldsymbol{\Gamma} \boldsymbol{X}_{t}+\boldsymbol{\epsilon}_{t} & & \boldsymbol{\epsilon}_{t} \sim \operatorname{NID}\left(\mathbf{0}, \boldsymbol{\Sigma}_{\epsilon}\right), \\
\boldsymbol{\mu}_{t} & =\boldsymbol{\mu}_{t-1}+\boldsymbol{\beta}_{t-1}+\boldsymbol{\eta}_{t}, & & \boldsymbol{\eta}_{t} \sim \operatorname{NID}\left(\mathbf{0}, \boldsymbol{\Sigma}_{\eta}\right) \\
\boldsymbol{\beta}_{t} & =\boldsymbol{\beta}_{t-1}+\boldsymbol{\zeta}_{t}, & & \boldsymbol{\zeta}_{t} \sim \operatorname{NID}\left(\mathbf{0}, \boldsymbol{\Sigma}_{\zeta}\right) \\
\boldsymbol{\psi}_{t} & =\rho \cos \lambda_{c} \boldsymbol{\psi}_{t-1}+\rho \sin \lambda_{c} \boldsymbol{\psi}_{t-1}^{*}+\boldsymbol{\kappa}_{t}, & \boldsymbol{\kappa}_{t} \sim \operatorname{NID}\left(\mathbf{0}, \boldsymbol{\Sigma}_{\kappa}\right) \\
\boldsymbol{\psi}_{t}^{*}=-\rho \sin \lambda_{c} \boldsymbol{\psi}_{t-1}+\rho \cos \lambda_{c} \boldsymbol{\psi}_{t-1}^{*}+\boldsymbol{\kappa}_{t}^{*}, & & \boldsymbol{\kappa}_{t}^{*} \sim \operatorname{NID}\left(\mathbf{0}, \boldsymbol{\Sigma}_{\kappa}\right)
\end{array}
$$

All the disturbances are mutually uncorrelated and uncorrelated with those in equation (91). Symbols in bold denote vectors; for instance, $\boldsymbol{\mu}_{t}=\left\{\mu_{i t}, i=1,2,3,4\right\}$ is the $4 \times 1$ vector containing the permanent levels of $f_{t}, p r_{t}, \mathrm{CUR}_{t}$, and $c_{t}$. The series display similar cycles, $\boldsymbol{\psi}_{t}$, that are such that the transmission mechanism of cyclical disturbances is common (the damping factor and the cyclical frequency are the same across the series). Common cycles arise when $\boldsymbol{\Sigma}_{\kappa}$ has reduced rank. The matrix $\boldsymbol{X}_{t}$ contains interventions that account for a level shift both in LFPR and CUR in 1992.4, an additive outlier (1984.4) and a slope change in capacity; $\boldsymbol{\Gamma}$ is the matrix containing their effects.

The output gap and potential output are then defined as linear combinations of the cycles and trends in (13):

$$
\mathrm{OG}_{t}=\left[\begin{array}{llll}
1, & \alpha, & -\alpha, & 0
\end{array}\right]^{\prime} \boldsymbol{\psi}_{t}, \quad \mathrm{PO}_{t}=\left[\begin{array}{llll}
1, & \alpha, & -\alpha, & 0
\end{array}\right]^{\prime} \boldsymbol{\mu}_{t}+\alpha n_{t}+(1-\alpha) k_{t} ;
$$

the former affects the changes in underlying inflation as specified in (9), which completes the model.

Model (13) features many sources of variation and needs to be restricted to produce reliable parameter estimates. The first restriction we impose is that the irregular component is present solely in the $f_{t}$ equation, that is $\boldsymbol{\epsilon}_{t}=\left[\epsilon_{1 t}, 0,0,0\right]^{\prime}$; this appears to is a mild and plausible restriction. The second enforces the stationarity of $c_{t}$ around a deterministic trend, possibly with a slope change, and amounts to zeroing out the elements of $\boldsymbol{\Sigma}_{\eta}$ and $\boldsymbol{\Sigma}_{\zeta}$ referring to $c_{t}$, and introducing a slope change variable in $\boldsymbol{X}_{t}$. We experimented with both cases in which $c_{t}$ is level stationary and stationary around a deterministic linear trend with a slope change, but it the sequel we are going to report only the second case, which produces better in sample fit and out of sample forecasts.

Next, we focus our attention on three constrained versions of the model (13)-(9), which impose additional restrictions on the trend component; the first features RW trends with 
constant drifts $\left(\boldsymbol{\Sigma}_{\zeta}=\mathbf{0}\right)$, the second specifies the trend as an integrated random walk (IRW), which amounts to setting $\boldsymbol{\Sigma}_{\eta}=\mathbf{0}$; the third is the damped slope model (DSlope), according to which the trends in $f_{t}, p r_{t}$, and $\mathrm{CUR}_{t}$ are specified as:

$$
\begin{aligned}
\mu_{i t} & =\mu_{i, t-1}+m_{i}+\beta_{i, t-1} \\
\beta_{i t} & =\phi_{i} \beta_{i, t-1}+\zeta_{i t},
\end{aligned}
$$

where $m_{i}$ is a constant, the damped slope parameter, $\phi_{i}$, is specific to each series, and the $\zeta_{i t}$ 's are NID disturbances that may be contemporaneously cross correlated across the series. The advantage of having different AR coefficients lies in the possibility of having different impulse responses to trend disturbances.

Apart from the DSlope specification, the appealing feature of the SUTSE trend-cycle decomposition is model invariance under contemporaneous aggregation, which means that output has the same univariate time series representation as in (8).

We now highlight a few estimation results; full results and parameter estimates are available from the authors. The best fit to the data is provided by the DSlope model, according to the diagnostics presented in table 4. The normality statistics are never significant for all the three specifications and are not presented; also, the coefficients associated to $\mathrm{OG}_{t}$ in the inflation equation are significant (for instance, in the IRW case $\tilde{\theta}_{\pi 0}=0.21$ and $\left.\tilde{\theta}_{\pi 1}=-0.16\right)$ and long run neutrality is rejected for all the specification. Similar considerations hold for the effects of the exogenous supply shocks.

It can be noticed that all the SUTSE models fail to account for the cyclical dynamics in $c_{t}$, as pointed out quite clearly by the Ljung-Box statistic. Moreover, the RW specification is seriously misspecified as far as $\mathrm{CUR}_{t}$ is concerned. The standardised Kalman filter innovations corresponding to $\mathrm{CUR}_{t}$ display positive and slowly declining autocorrelations and the Ljung-Box statistic calculated on the first eight autocorrelations is 93.91. The likely reason is that the orthogonal RW trend plus cycle decomposition imposes that the spectral density of $\Delta C U R_{t}$ is a minimum at the zero frequency, and, viewed from the frequency domain perspective, the model seriously underestimates the variance components around that frequency. Moreover, as we shall see later, the RW is characterised by a very poor forecasting performance.

For the IRW specification the cycles have a period of about six years $\left(\tilde{\lambda}_{c}=0.25\right)$ and $\tilde{\rho}=0.93$. This is noticeably shorter than that estimated from the bivariate models in section 7 . Some interesting estimation results are revealed by the spectral decomposition of the covariance matrices $\tilde{\boldsymbol{\Sigma}}_{\zeta}$ and $\tilde{\boldsymbol{\Sigma}}_{\kappa}$. For the former we have

\begin{tabular}{lrrrr}
\hline Eigenvalues of $10^{7} \times \tilde{\boldsymbol{\Sigma}}_{\zeta}$ & 4.61 & 0.47 & 0.00 & 0.00 \\
\hline \% of Total Variation & 90.81 & 9.19 & 0.00 & 0.00 \\
\hline \multirow{4}{*}{$f_{t}$} & 0.01 & 1.00 & 0.05 & 0.00 \\
$p r_{t}$ & 0.58 & 0.03 & -0.81 & 0.00 \\
CUR $_{t}$ & -0.81 & 0.04 & -0.58 & 0.00 \\
$c_{t}$ & 0.00 & 0.00 & 0.00 & 1.00 \\
\hline
\end{tabular}

which suggests the presence of only two sources of slope variation, the most relevant being associated with $p r_{t}$ and $\mathrm{CUR}_{t}$ and making them varying in opposite directions; the second, orthogonal to the first and characterised by a much smaller size, affects only $f_{t}$. 
As for the cyclical disturbances, the spectral decomposition of their covariance matrix resulted:

\begin{tabular}{lrrrr}
\hline Eigenvalues of $10^{7} \times \tilde{\boldsymbol{\Sigma}}_{\kappa}$ & 554.91 & 43.23 & 15.02 & 5.52 \\
\hline \% of Total Variation & 89.69 & 6.99 & 2.43 & 0.89 \\
\hline \multirow{4}{*}{$f_{t}$} & 0.34 & -0.91 & -0.23 & -0.00 \\
$n_{t}$ & -0.00 & 0.23 & -0.91 & -0.34 \\
CUR & -0.06 & 0.06 & -0.34 & 0.94 \\
$c_{t}$ & 0.94 & 0.33 & 0.06 & 0.06 \\
\hline
\end{tabular}

Hence, there is one source of cyclical variation that absorbs about $90 \%$ and can be identified with the cycle in $c_{t}$; this enters $f_{t}$ with a positive loading and $\mathrm{CUR}_{t}$ with a negative, although very small loading; the second source is less easily interpretable.

The DSlope specification gives results that are indistinguishable from IRW as far as the estimation of $\mathrm{OG}_{t}$ and $\mathrm{PO}_{t}$ are concerned; however, it is consistent with the single unit root hypothesis for $f_{t}, p r_{t}$ and $\mathrm{CUR}_{t}$; it is also noticeable that the autoregressive parameter estimated for the slope in $f_{t}$ is not significantly different from zero, whereas those for $p r_{t}$ and $\mathrm{CUR}_{t}$ are positive and high ( 0.9 for both). The spectral decompositions of the covariance matrices of the trend and cycle disturbances is analogous to that for IRW, pointing out only two sources of trend variation and a major source of cyclical variation accounting for $93 \%$ of total variation.

The smoothed components, along with the $\mathrm{OG}$ and $\mathrm{PO}_{t}$ estimates arising from the RW and IRW specifications are shown in the figures 4 and 5, respectively. While the cycle in $f_{t}$ is very similar, that in $p r_{t}$ and $C \mathrm{R}_{t}$ is much more variable in the $\mathrm{RW}$ case, whereas for IRW case most movements in the two variables are permanent. This is so since the latter allows the trend to move more rapidly and with greater persistence. Consequently, the OG has smaller amplitude and the labour makes a larger contribution to potential output growth.

\subsection{Common Cycle Specification}

The multivariate SUTSE models lended some support for the presence of a common cycle that is driven by capacity; as a matter of fact, capacity utilisation is one of the determinants of the series $f_{t}$, along with hours worked and total factor productivity. Consequently, we expect that a substantial part of its cyclical variation is common to that in $c_{t}$, which represent a survey based measure of capacity utilisation. Taking the cycle in capacity as the reference cycle, we write

$$
c_{t}=m(t)+\psi_{t}
$$

where $m(t)$ is a deterministic trend with a slope change in 1975.1, and

$$
\psi_{t}=\phi_{1} \psi_{t-1}+\phi_{2} \psi_{t-2}+\kappa_{t}, \quad \kappa_{t} \sim \operatorname{NID}\left(0, \sigma_{\kappa}^{2}\right),
$$

acts as the common cycle; this has a second order autoregressive representation; for estimation purposes we impose complex stationary roots expressing $\phi_{1}=2 \rho \cos \lambda_{c}$ and $\phi_{2}=-\rho^{2}$, where $\rho$ and $\lambda_{c}$ (representing the modulus and the phase of the roots of the 
characteristic equation), lie respectively in $[0,1)$ and $[0, \pi]$. This representation is similar to the model for the stochastic cycle formulated in (8), but differs in that it is devoid of the MA feature which characterises the latter, as can be deduced from the reduced form. As a consequence (15) defines a slightly smoother cycle when $\lambda_{c}$ is less than $\pi / 2$. Its typical spectral shape is plotted in the right panel of figure 7 .

The transitory components in $f_{t}, p r_{t}$ and $\mathrm{CUR}_{t}$ are expressed as a linear combination of the current and the lagged value of $\psi_{t}$ :

$$
\psi_{i t}=\theta_{i}(L) \psi_{t}, \quad \theta_{i}(L)=\theta_{i 0}+\theta_{i 1} L,
$$

where $i=1,2,3$, indexes the three variables. Notice that $\mathrm{OG}_{t}=\psi_{1 t}+\alpha \psi_{2 t}-\alpha \psi_{3 t}$ yields again an $\operatorname{ARMA}(2,1)$ process, as in (8) and (13), with the difference that now the MA polynomial is unrestricted.

A second cycle, orthogonal to $\psi_{t}$, was added with the explicit intent to capture the residual cyclical variation, but it turned out to capture a seasonal stationary cycle in CUR $_{t}$; this effect can be ascribed to underadjustment of the series for the individual countries and disappears after the major revision in the series that took place in 1992.4.

The permanent components in $f_{t}, p r_{t}$ and CUR $_{t}$ were specified as IRW and as I(1) processes with a damped slope (DSlope) trends (see equation (14)); the results are very similar and we will mostly refer to the former.

Selected estimation results are reported in table 5. The common cycle parameters were $\tilde{\phi}_{1}=1.74, \tilde{\phi}_{2}=-0.84$ and $\tilde{\sigma}_{\kappa}^{2}=255 \times 10^{-7}$. As in the SUTSE case this defines a cycle with a smaller period compared to that estimated by bivariate models of output and inflation. The fit is satisfactory, especially for the DSlope specification: residual autocorrelation is low with only one significant autocorrelation at lag 1 for $c_{t}$, which is quite remarkable for that series. Again, we do not report the normality statistics, as they were never significant. The variables load significantly on the common cycle (with a lagged response for $p r_{t}$ ), but yet the bulk of the dynamics in $p r_{t}$ and CUR $\mathrm{R}_{t}$ are permanent, as can be seen from the plot of the smoothed components in figure 6, which refers to the IRW trend specification. As a consequence, labour makes a large contribution to potential output growth and affects very little the output gap, which is largely dependent on the transitory component of $f_{t}$. This was also true for the SUTSE models with IRW and DSlope trends, but with respect to those, the uncertainty surrounding the OG and PO estimates is much reduced, which is a simple consequence of imposing a common cycle.

The bottom line of table 5 gives the estimate of the coefficients associated to the output gap OG in the triangle model for inflation. The usual considerations apply: the output gap makes a significant contribution, such that the change effect is considerable and the level effect, although significant, has little impact on the long run path of inflation.

The table also reports the autoregressive coefficients of the damped slope model (14): this is estimated as zero for $f_{t}$, so that the trend is a RW with constant drift and it is large and positive for $p r_{t}$ and $\mathrm{CUR}_{t}$, the evidence being that trend disturbances are more persistent for the latter.

\subsection{Hysteresis}

As we have seen, the dynamics in $p r_{t}$ and $C U R_{t}$ are largely permanent. This phenomenon is often referred to as hysteresis, although the term is attached different meanings. For 
unemployment it is used to signify the absence of any tendency to revert to the same mean value after a shock. Accordingly, the natural rate of unemployment is time varying and possibly highly persistent. This does not necessarily imply that the series is not affected by the business cycle; it might be the case that the cyclical shocks modify permanently the long run path.

We can investigate this issue by a modification of the common cycle model, according to which the underlying cycle enters the trend equation rather than the levels of the series:

$$
\begin{array}{lll}
\mu_{i t}=\mu_{i, t-1}+\vartheta_{i}(L) \psi_{t}+m+\beta_{i, t-1}, & & i=1,2,3, \\
\beta_{i t}^{*}=\phi_{i} \beta_{i, t-1}+\zeta_{i t}, & & \zeta_{i t} \sim \operatorname{NID}\left(0, \sigma_{\zeta, i}^{2}\right)
\end{array}
$$

where again $i$ indexes the series $f_{t}, p r_{t}$ and $C_{U}$. According to (16) there are two identifiable sources of trend variation, the first associated to the cycle in capacity and an independent source, modelled as a first order autoregression (DSlope) or a random walk (I(2)), which arises by setting $\phi_{i}=1, m=0$. The $\zeta_{i t}$ 's are allowed to be contemporaneously correlated.

If $\vartheta_{i}(L)$ is a second order lag polynomial, then it admits the following decomposition:

$$
\vartheta_{i 0}+\vartheta_{i 1} L+\vartheta_{i 2} L^{2}=\vartheta(1) L+\Delta \theta_{i}(L)
$$

where $\theta_{i}(L)=\theta_{i 0}+\theta_{i 1} L$, with $\theta_{i 0}=\vartheta_{i 0}$ and $\theta_{i 1}=\vartheta_{i 0}+\vartheta_{i 1}$, so that we can extract a cycle in the levels by writing:

$$
\begin{array}{rlr}
y_{i t} & =\mu_{i t}^{*}+\psi_{i t}, & i=1,2,3 \\
\mu_{i t}^{*} & =\mu_{i, t-1}^{*}+\vartheta_{i}(1) \psi_{t-1}+m+\beta_{i, t-1}, & \\
\beta_{i t} & =\phi_{i} \beta_{i, t-1}+\zeta_{i t}, & \\
\psi_{i t} & =\theta_{i}(L) \psi_{t} .
\end{array}
$$

OG and PO are still defined as a linear combination of $\psi_{i t}$ and $\mu_{i t}^{*}$, respectively, but will no longer be orthogonal, unless $\vartheta_{i}(1)=0$, for all $i$, in which case the model is equivalent to the common cycle model of section 8.2. Hence, the test of $\vartheta_{i}(1)=0$ can be used to assess the hysteresis phenomenon. Model (17) is the Jäger and Parkinson (1994) hysteresis model.

The estimation results, reported in table 6 lead to accept the hysteresis hypothesis for $\mathrm{CUR}_{t}$, whereas the results are mixed for $p r_{t}$, as they depend on the specification of the slope component. Hysteresis is clearly rejected for $f_{t}$, for which an orthogonal cycle can be extracted. The trend-cycle decomposition of the variable does not differ much from that resulting from the common cycle models, with $p r_{t}$ and $\mathrm{CUR}_{t}$ contributing little to $\mathrm{OG}_{t}$; as a matter of fact, the estimates of the loading on $\psi_{t}$ implied by the estimates of the $\vartheta_{i}(L)$ polynomials are remarkably similar to those displayed in table 5 for instance, with respect to $p r_{t}\left(\mathrm{I}(2)\right.$ case) we have $\tilde{\theta}_{i 0}=\tilde{\vartheta}_{i 0}=-0.04$ and $\tilde{\theta}_{i 0}=\tilde{\vartheta}_{i 0}+\tilde{\vartheta}_{i 1}=0.09$. Only for CUR the loading is slightly bigger, since $\tilde{\theta}_{i 0}=-0.11$, and $\tilde{\theta}_{i 0}=0.00$.

\subsection{Pseudo-Integrated Cycles}

We have seen that one of the major problems is eliciting cyclical variability in the labour variables. This may be due to the fact that the cycle in those series is more persistent, albeit still stationary, than that in capacity. The idea is that cyclical information 
can be propagated to other variables according to some transmission mechanism which acts as a filter on the driving cycle; to make this assertion more precise, we present the representation of the cycle in the $i$-th variable $(i=1,2,3)$ that encapsulates it:

$$
\begin{array}{lll}
\psi_{i t}=\rho_{i} \cos \lambda_{i} \psi_{i, t-1}+\rho_{i} \sin \lambda_{i} \psi_{i, t-1}^{*}+\theta_{i}(L) \psi_{t}+\kappa_{i t}, & \kappa_{i t} \sim \operatorname{NID}\left(0, \sigma_{\kappa, i}^{2}\right) \\
\psi_{i t}^{*}=-\rho_{i} \sin \lambda_{i} \psi_{i, t-1}+\rho_{i} \cos \lambda_{i} \psi_{i, t-1}^{*}+\kappa_{i t}^{*}, & \kappa_{i t}^{*} \sim \operatorname{NID}\left(0, \sigma_{\kappa, i}^{2}\right)
\end{array}
$$

where $\psi_{t}$ is the cycle in capacity utilisation (or, more generally, a coincident index of business cycle conditions), $\kappa_{i t}$ and $\kappa_{i t}^{*}$ are idiosyncratic disturbances, mutually uncorrelated and homoscedastic, $\rho_{i}$ is a damping factor and $\lambda_{i}$ a frequency in the range $(0, \pi)$.

We refer to (18) as a pseudo-integrated cycle. Model (18) encompasses several leading cases of interest:

1. If $\theta_{i}(L)=0$, (18) defines a fully idiosyncratic cycle with frequency $\lambda_{i}$, damping factor $\rho_{i}$ and disturbance variance $\sigma_{\kappa, i}^{2}$.

2. If $\rho_{i}=0$ and $\sigma_{\kappa, i}^{2}=0$ the $i$-th cycle reduces to a model with a common cycle, that is $\psi_{i t}=\theta_{i}(L) \psi_{t}$, as in section 8.2 .

3. If $\rho_{i}=\rho, \lambda_{i}=\lambda_{c}$ and $\sigma_{\kappa}^{2}=0$ the $i$-th cycle has the representation $\left(1-2 \rho \cos \lambda_{c} L+\right.$ $\left.\rho^{2} L^{2}\right)^{2} \psi_{i t}=\theta_{i}(L) \kappa_{t}$, which defines a smooth cycle with a sharper peak at $\lambda_{c}$. Harvey and Trimbur (2002) refer to it as a second order cycle, in the context of designing band-pass filters in an unobserved components framework.

In general, according to (18), the $i$-th cycle is driven by a combination of autonomous forces and by the common cycle; their impulse is propagated via an autoregressive mechanism. The corresponding spectral density can be bimodal or more spread around some frequency. The right panel of figure 8 displays the spectral density implied for the $\mathrm{CUR}_{t}$ series, for which $\lambda_{i}=0$ and $\rho_{i}=0.91$, so that

$$
\left(1-\rho_{i} L\right) \psi_{i t}=\theta_{i}(L) \psi_{t}+\kappa_{i t}
$$

The results from fitting multivariate PFA models with pseudo-integrated cycles and alternatively IRW and DSlope trend are reported in table 7. For the IRW specification the cycle driving that is pseudo-integrated in the $\psi_{i t}$ 's for $f_{t}, p r_{t}$ and $\mathrm{CUR}_{t}$ is

$$
\psi_{t}=1.73 \psi_{t-1}-0.83 \psi_{t-2}+\kappa_{t}, \quad \kappa_{t} \sim \operatorname{NID}\left(0,254 \times 10^{-7}\right),
$$

and implies a spectral peak at the frequency 0.31 corresponding to a period of five years (see figure 8). The specific damping factor, $\rho_{i}$ is similar for $p r_{t}$ and $\mathrm{CUR}_{t}$ and it is substantially lower for $f_{t}$; the estimated frequencies $\tilde{\lambda}_{i}$ resulted equal to zero, and the idiosyncratic variation is small, the exception being $\tilde{\sigma}_{\kappa, i}$ for $f_{t}$ in the IRW case. The slope disturbances, $\zeta_{i t}$, for the labour variables are now perfectly correlated and orthogonal to those in $f_{t}$; moreover, the AR coefficients in the DSlope specification are practically equal to one. Therefore, the trend in $p r_{t}$ and $C U R_{t}$ is effectively an integrated random walk.

The two specifications differ only for the trend-cycle decomposition of $f_{t}$ : in the DSlope case, the trend is a random walk with constant drift, and absorbs part of the variability that IRW assigns to the cycle.

The individual components and the corresponding OG and PO growth estimates are plotted in figure 8, which refers to IRW. As expected, the model is capable of extracting 
more cyclical variability from the series. Correspondingly, the PO growth estimates are smoother; higher uncertainty, resulting in wider confidence bounds, is the price we have to pay for enhancing smoothness.

The last row of table 7 reports the estimated loadings of underlying inflation on the output gap; their relatively small size depends on the fact that the estimated output gap has greater amplitude, i.e. it represents a greater portion of output, than it had for the common cycle case; the Wald test for long run neutrality resulted 18.64, which is highly significant.

\subsection{Comparison of forecast performance and discussion}

Table 8 reports the mean forecast error and the root mean square error, relative to that of the benchmark model (12), resulting from the rolling forecast experiment exposed in section 7.2, aiming at assessing the predictive accuracy of the various models implementing the production function approach, the target variable being the annual inflation rate.

The models under scrutiny are the three SUTSE model with different trend specifications, and the two versions of common cycle, hysteresis and pseudo-integrated cycle models that were discussed in the previous sections.

The main evidence is that the PFA models outperform the benchmark only at very short forecast leads; it never outperforms the Unrestricted bivariate model of output and inflation (compare with results in table 2).

Within the PFA approach it is difficult to discriminate the predictive accuracy of the various alternatives, apart from the fact that the SUTSE model with RW trends seems to be characterised by a decisively worse performance in terms of root mean square error, and this has to be ascribed to the large forecasting biases which affect it. Moreover, specifying $I(2)$ trends improves slightly out of sample forecast accuracy, except for the hysteresis case. While it is quite plausible that the SUTSE, Common Cycle and Hysteresis models should perform similarly, as they imply similar OG estimates, drawing little information on labour, it is noticeable that the pseudo-integrated model gives similar results.

In conclusion, the assessment of predictive accuracy leaves us uncertain as to the best characterisation of key macroeconomic concepts such as potential output and the output gap. In the next section we discuss how the uncertainty issue can be dealt with using unobserved components methods.

Although the PFA approach cannot outperform a simple bivariate model of output and inflation it reduces substantially the uncertainty in the estimates of the output gap and enables the breakdown of potential output growth into the three determinants: the Solow's residual, capital and labour (growth accounting); figure 9 shows the contribution of the three factors for the common cycle and the pseudo-integrated cycle models with IRW trends, highlighting the differences between the two. One piece of evidence that is robust is that the increase in PO growth in the last decade has to be ascribed to labour, whereas the decline in the 70ies and the 80ies is due to decreasing rates of capital and productivity growth.

The relatively poor performance of the PFA approach could be ascribed to two factors: the first is the restrictive nature of the assumptions about technology: the approach is based on a specific production function with constant returns to scale, that is however amenable to statistical treatment, and we assumed that the elasticity of output with 
respect to labour was constant and equal to labour's output share. We leave to future research the issue of investigating alternative functional forms (at the cost of making the model nonlinear) and estimating core technology parameters. The second can be discerned from the plot of the estimates of $\mathrm{OG}_{t}$ implied by PFA models: we have already stressed that they are characterised by a much smaller period with respect to that implied by bivariate models of output and inflation and, as a matter of fact, during the test period, starting from 1995.1, the PFA estimates display three full cycles of comparable amplitude, of which only the last (around the turn of the century) corresponded to effective inflationary pressures. In conclusion, the PFA OG $t$ estimates overemphasise the inflationary pressures in 1994-1999, which is a period of deflation, as can be seen from the last panel of figure 3 .

\section{Reliability of Potential and Output Gap esti- mates}

In an unobserved components framework, smoothing algorithms provide the standard error of $\mathrm{PO}_{t}$ and $\mathrm{OG}_{t}$, thereby allowing a direct assessment of their uncertainty. Understandably, there is great concern over this point for policy matters, and below we argue that unobserved components methods can trace some crucial aspects of the uncertainty.

Orphanides and van Norden (1999) and Cambda-Mendez and Rodriguez-Palanzuela (2001) propose the following taxonomy of the possible sources of uncertainty in estimating latent variables, such as the output gap:

1. data revision

2. model uncertainty

3. parameter uncertainty

4. final estimation error

5. statistical revision

The first source deals with the uncertainty arising from revisions in the raw data due to accrual of more information (this is thoroughly investigated in Orphanides and van Norden, 1999), revision in quarterly estimates of national accounts due to distribution of annual figures, seasonal adjustment and other infinite impulse response filters, changes in the definition of macroeconomic aggregates.

The previous sections testify the kind of model uncertainty that the investigator faces when estimating key macroeconomic latent variables: model assessment can be based on the ability to forecast inflation, which however is one of the uses of the model; out of sample forecasting performance is indeed a good test that is consistent with the notion of the output gap as a measure of inflationary pressure. Nevertheless, the production function approach reduces the uncertainty of the estimates and yields as a by product the contribution of labour, capital and total factor productivity to potential output growth.

The uncertainty remains even if we restrict our domain to the models implementing the PFA: the common cycle model, that is such that labour makes most of its contribution to potential output, and the pseudo-integrated cycle model, according to which labour contributes more substantially to the output gap, are virtually indistinguishable on the 
basis of their goodness of fit and forecasting performance. A smoothness prior on potential output growth might be advocated to select the latter, but what if we do not want to impose it?

As in forecasting, the uncertainty can be reduced by combining the estimates: the optimal weights can be straightforwardly obtained if one knew the covariance matrix of the estimates arising from different models, but this is of course not directly available, since the models are estimated independently. For this purpose we make the following proposal: suppose that $\tilde{O G}_{j t}=\mathrm{E}\left(\mathrm{OG}_{t} \mid \mathcal{F}_{T}, M_{j}\right)$ denotes the smoothed estimate of the output gap at time $t$ produced by model $j\left(M_{j}\right)$; for each model $j$ and each $t$, the algorithm known as the simulation smoother (De Jong and Shepard, 1994) enables to draw repeated sample from the distribution of $\mathrm{OG}_{j t}$ conditional on the available series and $M_{j}$; let us denote the draws by $\tilde{O G}_{j t}^{(k)}, k=1, \ldots, K$. The replications can be used to estimate the covariance matrix of the estimates arising from the different models, say $\boldsymbol{V}_{t}$, with $(j, l)$ element:

$$
v_{j l, t}=\frac{1}{K} \sum_{k=1}^{K}\left(\tilde{O G}_{j t}^{(k)}-\tilde{O G}_{j t}\right)\left(\tilde{O G}_{l t}^{(k)}-\tilde{O G}_{l t}\right) \text {. }
$$

The set of weights, summing up to one, that are used to produce the the combined estimate $\sum_{j} w_{j t} \tilde{\mathrm{OG}}_{j t}$ with minimal variance can be easily shown to be equal to:

$$
\boldsymbol{w}_{t}=\frac{1}{\boldsymbol{i}^{\prime} \boldsymbol{V}_{t}^{-1} \boldsymbol{i}} \boldsymbol{V}_{t}^{-1} \boldsymbol{i}, \quad\left(\boldsymbol{w}^{\prime} \boldsymbol{i}=1\right),
$$

where $\boldsymbol{i}$ denotes a vector of ones.

The remaining sources can also be thoroughly assessed within the state space methodology. For an unobserved component the Kalman filter and smoother deliver the minimum mean square linear estimate conditional on the available sample and the maximum likelihood estimate of the parameters of the model, say $\tilde{\boldsymbol{\theta}}$; the latter is such that asymptotically $\tilde{\boldsymbol{\theta}} \sim \mathrm{N}\left(\boldsymbol{\theta}, \boldsymbol{V}_{\theta}\right)$, where $\boldsymbol{V}_{\theta}$ is the covariance matrix of the ML estimates.

Given a signal in macroeconomics, $\varsigma_{t}$, the fixed interval smoother thus provides $\mathrm{E}\left(\varsigma_{t} \mid \mathcal{F}_{T}, \tilde{\boldsymbol{\theta}}\right)$, $\operatorname{Var}\left(\varsigma_{t} \mid \mathcal{F}_{T}, \tilde{\boldsymbol{\theta}}\right)$. We can account for parameter uncertainty by looking at the posterior moments of the signal unconditional on $\tilde{\boldsymbol{\theta}}$ :

$$
\mathrm{E}\left(\varsigma_{t} \mid \mathcal{F}_{T}\right)=\mathrm{E}_{\tilde{\theta}}\left[\mathrm{E}\left(\varsigma_{t} \mid \mathcal{F}_{T}, \tilde{\boldsymbol{\theta}}\right)\right], \quad \operatorname{Var}\left(\varsigma_{t} \mid \mathcal{F}_{T}\right)=\operatorname{Var}_{\tilde{\theta}}\left[\mathrm{E}\left(\varsigma_{t} \mid \mathcal{F}_{T}, \tilde{\boldsymbol{\theta}}\right)\right]+\mathrm{E}_{\tilde{\theta}}\left[\operatorname{Var}\left(\varsigma_{t} \mid \mathcal{F}_{T}, \tilde{\boldsymbol{\theta}}\right)\right],
$$

where the subscript stresses that the moments on the right hand side are evaluated with respect to the distribution of $\tilde{\boldsymbol{\theta}}$. The unconditional moments can by evaluated by stochastic simulation techniques, drawing a large number of independent samples $\tilde{\boldsymbol{\theta}}^{(k)} \sim \mathbf{N}\left(\tilde{\boldsymbol{\theta}}, \boldsymbol{V}_{\theta}\right), k=1, \ldots, K$, and using the fixed interval smoother to evaluate the moments of the signal conditional on the draws.

Our experience is that this source of uncertainty is overstated, to a certain extent. For instance for the PFA model with common cycle and damped slopes of section 8.2 the standard error of the $\mathrm{OG}_{t}$ estimates around the middle of the sample conditional on the maximum likelihood estimates is 0.0036 , whereas the unconditional one (estimated on the basis of 5000 replications) is 0.0039 .

Finally, a thorough assessment of the role of revisions can be made in the state space framework using a fixed point smoother (see De Jong, 1991). This could be used to 
establish, for instance, the percentage reduction in the estimation error variance due to the accrual of additional information. A general rule is that smoother signals are prone to higher revisions, and this suggests that the standard errors of the estimates will provide a preliminary assessment of their relative importance. Smoothness of the signal is usually at odds with its reliability, unfortunately, and this has to be brought in mind when imposing smoothness priors on the components. Nevertheless, given the structure the measurement model, the availability of future observations reduces the estimation error; hence, in the absence of structural breaks, statistical revisions are sound and a fact of life, i.e. a natural consequence of optimal signal extraction. However, the reliability of the signal can be increased at the end of the sample if the observed series is extended with forecasts that are more informative than the model's forecasts.

\section{Conclusions}

This paper evaluated a system-based unobserved components model for estimating potential output and the output gap for the Euro Area. As a benchmark we estimated two types of unoserved components models that feature prominently in the literature. These were a univariate decomposition of output into a trend and a cyclical component, and a bivariate model of output and inflation where the two variables are linked via the output gap. Against these benchmarks we fitted and validated multivariate unobserved components models explicitly based on the production function approach. More specifically, we estimated systems of five time series equations, namely for total factor productivity, the labour force participation rate, the employment rate, capacity utilisation and the consumer price index. The first four equations define the output gap, conditional on the price equation which relates the output gap to underlying inflation according to a variant of Gordon's triangle model.

For both the benchmark models and the system-based multivariate models we tested several specifications, encompassing a wide range of economic interpretation, by imposing restrictions on the model parameters and by imposing priors on the cyclical and trend components. In a number of cases we found it difficult to discriminate between the different specifications solely on the basis of fit and estimation results. As a performance indicator we therefore used the accuracy of the specifications in predicting inflation in a rolling forecasting experiment. In addition, we looked at the uncertainty bands of the estimates as a selection criterion.

Our findings are the following. Judging from the root mean square errors, the predictive accuracy does not vary much between the individual specifications of the productionfunction based model and can thus give not much guidance in selecting the best representation of trend (potential output) and cycle (output gap) within the system approach. At the same time, starting from a system of seemingly unrelated equations, this allowed for incorporating restrictions that correspond to some of our economic priors without a loss in forecasting accuracy. One such prior was the hypothesis of a common cycle driven by capacity utilisation in the cyclically sensitive manufacturing sector, an additional one was the hysteresis hypothesis according to which cyclical shocks may have a permanent impact on the trends. The latter was found to be relevant for the labour market variables for which the bulk of the dynamics proved to be permanent. While not increasing 
forecasting accuracy, these restrictions tended to reduce the uncertainty surrounding the potential output and output gap estimates. Given the problem that the different specifications tended to extract too little cyclical variability from, in particular, the labour market variables we also tested a model specifications with pseudo-integrated cycles that proved quite effective in enhancing the smoothness in potential output. The results from the pseudo-integrated cycle specification were virtually indistinguishable from the common cycle and hysteresis specifications in terms of goodness of fit and forecasting performance and also generated a relatively smooth potential output series. Such smoothness would be in line with the view that potential output growth represents the longer-term growth path of the economy and is not expected to vary much between individual years, but the cost of achieving this was a wider confidence bands around the estimates. In policy applications this would imply a trade-off between possibly more plausible economic results and higher uncertainty.

Compared with the benchmark models we found that the production-function based model can compete with bivariate models of output and inflation only at a forecast lead of one quarter, but performed increasingly worse once the forecast horizon started to exceed one quarter. The unrestricted bivariate model of output and inflation always outperformed the production function-based model. Finally, for horizons beyond two years the bivariate models do not outperform a univariate model for the consumer price index. In turn, the production function-based models implied lower uncertainty for the estimates of the output gap.

Overall, the results confirm the economically trivial but statistically not always straightforward perception that more information reduces estimation uncertainty. In this respect the bivariate models outperform univariate models and the production function based models outperform the bivariate models. At the same time, forecasting accuracy speaks in favour of the bivariate models. This shows that in applying these models, users such as policy makers are faced with the trade off between higher forecast accuracy and lower uncertainty. Overlaying this is a second trade-off, namely that between achieving estimates of smoother potential output growth and incurring higher uncertainty surrounding these estimates.

For policy makers, the production function based model has the advantage of being grounded on economic theory and - due to the relative richness of included variables - of facilitating the interpretation of perceived developments in potential output and output gaps. This is all the more the case as it generates as a by-product estimates of a structural rate of unemployment and a measures of underlying inflation, both of which can be assessed in terms of their economic plausibility. One way of remedying the relative deficiencies of the production function model in terms of forecasting accuracy would be to combine it with the estimates of the more successful models, using optimal weights, but this is an area that we leave for future research. 


\section{References}

Akerlof G., Perry, G. and W. Dickens (1996), "The Macroeconomics of Low Inflation", Brookings Papers on Economic Activity, 1:1996.

Apel, M., and Jansson, P. (1999), "A Theory-Consistent System Approach for Estimating Potential Output and the NAIRU", Economics Letters, 64, 271-275.

Artus, P. (1977), "Measures of potential output in manufacturing for eight industrial countries, 1955-78", IMF Staff Papers v.24, March 1977, pp. 1-35.

Blanchard, O. (1997): "Medium Run", Brookings Papers on Economic Activity, pp. 89-141.

Blanchard O., A. Blinder, M. Eichenbaum, Solow, R. and J. Taylor (1997), Symposium on "Is there a core of practical macroeconomics that we should all believe?", American Economic Review Papers and Proceedings, 87(2), pp. 230-246.

Blanchard, O. and Katz L. (1999), "Wage Dynamics: Reconciling Theory and Evidence", American Economic Review 89(2), 69-74.

Blanchard, O. and Quah, D. (1989), "The dynamic effects of aggregate demand and aggregate supply disturbances", American Economic Review, 79, 65358.

Beveridge, S., Nelson, C.R. (1981), "A new Approach to the Decomposition of Economic Time Series into Permanent and Transitory Components with Particular Attention to the Measurement of the "Business Cycle", Journal of Monetary Economics, 7, 151-174.

Busetti, F. and Harvey, A.C. (2001), "Testing or the presence of a random walk in series with structural breaks", Journal of Time Series Analysis, 22, 127-150.

Canova, F. and Hansen, B.E. (1995), "Are seasonal patterns constant over time? A test for seasonal stability", Journal of Business and Economic Statistics, 2, 292-349.

Camba-Mendez, G., and Rodriguez-Palenzuela, D. (2001), "Assessment Criteria for Output Gap Estimates", ECB Working Paper No. 54, European Central Bank.

CBO, Congressional Budget Office (1995), "CBO's Method for Estimating Potential Output", CBO Memorandum, Washington, U.S.

de Jong, P. (1989), "Smoothing and Interpolation with the State Space Model", Journal of the American Statistical Association, 84, 1085-1088.

de Jong, P., and Shephard, N.G. (1995), "The simulation smoother for time series models", Biometrika, 82, 339-350.

de Masi, P. (1997), "IMF Estimates of Potential Output: Theory and Practice", IMF Working Paper, 177, International Monetary Fund. 29, 1-16.

DeSerres, A., Guay, A., St-Amant, P. (1995), "Estimating and projecting potential output using structural VAR methodology: the case of the Mexican economy". Bank of Canada, Working paper 92/2.

Espinosa-Vega M. A. and S. Russell, 1997. "History and theory of the NAIRU: a critical review," Economic Review, (Q II) pp. 4-25. Federal Reserve Bank of Atlanta. 
Doornik, J.A. (2001), Ox. An Object-Oriented Matrix Programming Language, Timberlake Consultants Press, London.

Doornik, J.A. Hansen H., (1994), "An omnibus test for univariate multivariate normality". Discussion paper, Nuffield College, Oxford.

Durbin, J., and Koopman, S.J. (2001), Time Series Analysis by State Space Methods, Oxford University Press, Oxford, UK.

Ehrmann, M., and Smets, F. (2001), "Uncertain potential output: implications for monetary policy", ECB Working Paper No. 59, April 2001,;

Eisner, R. (1997), "A new view of the NAIRU." In P. Davidson and J. Kregel (eds.), Improving the Global Economy: Keynesianism and the Growth in Output and Employment. Cheltenham U.K.: Edward Elgar.

European Commission (2000), European Economy, Directorate-General for Economic and Financial Affairs, 2000, Number 3.

Fagan G., J. Henry, R. Mestre (2001): "An area-wide model (AWM) for the euro area", ECB Working Paper No. 42, January 2001.

Fair R. (2000): "Testing the NAIRU Model for the United States", The Review of Economics and Statistics, February 2000, 64-71.

Freedman, C. (1989): "Monetary policy in the 1990s: lessons and challenges", in Monetary policy issues in the 1990s, Proceedings of the Federal Reserve Bank of Kansas, pp. 1-53.

Friedman, M. (1968): "The Role of Monetary Policy", American Economic Review, v. 58, :pp.1-17.

Gali, J. (2002): "New Perspectives on Monetary Policy, Inflation, and the Business Cycle", NBER Working Paper No.8767, February 2002.

Gerlach, S., and Smets, F. (1999): "Output Gaps and Monetary Policy in the EMU Area", European Economic Review, 43, 801-812.

Giorno, C., Richardson, P., Roseveare, D., and van den Noord, P. (1995), "Estimating Potential Output, Output Gaps and Structural Budget Balances", OECD Economics Department Working Paper No. 152, Paris.

Gordon, R.J. (1984), "Unemployment and the Growth of Potential Output in the 1980s," Brookings Papers on Economic Activity, vol 15, no. 2), pp. 537-64.

Gordon, R.J. (1997), "The Time-Varying NAIRU and its Implications for Economic Policy", Journal of Economic Perspectives, 11 (2), 11-32.

Gordon R.J. (1998), "Foundations of the Goldilocks Economy: Supply Shocks and the Time-Varying NAIRU", Brookings Papers on Economic Activity, no.2, pp. 297-346.

Greenslade J.V., Hall, S.G., Nixon, J. and S. G. B. Henry (2000), "Unemployment, the natural rate and structural change", in Holly, S. and M. Weale (eds.) Econometric Modelling. Techniques and Applications, Cambridge University Press, Cambridge, U.K.

Haltmaier, J.T. (1996), "Inflation Adjusted Potential Output", International Finance Discussion Papers No. 561, Board of Governors of the Federal Reserve System. 
Harvey, A.C. (1989), Forecasting, Structural Time Series and the Kalman Filter, Cambridge University Press, Cambridge, UK.

Harvey, A.C. (2001), Testing in unobserved components models, Journal of Forecasting, 20, 1-19.

Harvey, A.C., and Trimbur, T. (2002), "General model-based filters for extracting trends and cycles in economic time series", Review of Economics and Statistics (to appear).

Harvey, A.C., and Jäger, A. (1993), Detrending, stylized facts and the business cycle", Journal of Applied Econometrics, 8, 231-247.

Hodrick R.J., and Prescott, E.C. (1997), "Postwar U.S. Business Cycles: an Empirical Investigation", Journal of Money, Credit and Banking, 29, 1-16.

Issing O., Gaspar, V., Angeloni, I. and O. Tristani (2001), Monetary Policy in the Euro Area Strategy and Decision-Making at the European Central Bank, Cambridge University Press, Cambridge, U.K.

Jäger, A., and Parkinson, M. (1994), "Some Evidence on Hysteresis in Unemployment Rates", European Economic Review, 38, 329-342.

King, R.G. and Rebelo, S.T. (1993), Low frequency filtering and real business cycles", Journal of Economic Dynamics and Control, 17, 207-231.

Kim, C-J., and Nelson, C.R (1999), "Has the U.S. Economy become more Stable? A Bayesian Approach based on a Markov-Switching Model of the Business Cycle", The Review of Economics and Statistics, 81, 608-616.

Koopman S.J., Shepard, N., and Doornik, J.A. (1999), "Statistical algorithms for models in state space using SsfPack 2.2", Econometrics Journal, 2, 113-166.

Koopman S.J., Harvey, A.C., Doornik, J.A., and Shephard, N. (2000), STAMP 6.0 Structural Time Series Analyser, Modeller and Predictor (London, Timberlake Consultants Ldt., 2000).

Kuttner, K.N. (1994), "Estimating potential output as a latent variable", Journal of Business and Economic Statistics, 12, 361-368.

Kwiatkowski, D., Phillips, P.C.B., Schmidt, P., and Shin, Y. (1992), "Testing the null hypothesis of stationarity against the alternative of a unit root: How sure are we that economic time series have a unit root?", Journal of Econometrics 54, 159-178.

Laxton, D., and Tetlow, R. (1992), A Simple Multivariate Filter for the Measurement of Potential Output, Bank of Canada Technical Report No. 59, Bank of Canada, Ottawa.

Layard, R., Nickel, S. and R. Jackman (1991), Unemployment, Oxford University Press, Oxford.

Nelson, E. and K. Nikolov (2001): "UK inflation in the 1970s and 1980s: the role of output gap mismeasurement", Bank of England, WP n.148.

Okun A. (1962): "Potential GNP: Its Measurement and Significance", 1962 Proceedings of the Business and Economic Statistics Section of the American Statistical Association. Reprinted in Okun A., The Political Economy of Prosperity, pp.132-45. New York: Norton, 1970. 
Orphanides, A. (2001): "Monetary Policy Rules Based on Real-Time Data", American Economic Review, 91(4), pp.964-85.

Orphanides, A., van Norden, S. (1999), "The Reliability of Output Gap Estimates in Real Time", Finance and Economics Discussion Series, Board of Governors of the Federal Reserve System, Washington.

Phelps, E.S. (1968), "Money-Wage Dynamics Dynamics and Labor-Market Equilibrium", Journal of Political Economy, v. 6, pp.678-711.

Phillips, A. W. (1958), "The Relation Between Unemployment and the Rate of Change of Money Wage Rates in the United Kingdom, 1861-1957", Economica, 25, 283-99.

Rudebusch G. and L. Svensson (1999), "Policy Rules for Inflation Targeting", In Taylor, J. (ed.), Monetary Policy Rules, University of Chicago Press, 203-246.

Rünstler, G. (2002), "The Information Content of Real-Time Output Gap Estimates. An Application to the Euro Area" Working paper, European Central Bank, Directorate General Research, Frankfurt am Main.

Smets F (2000), "What horizon for price stability", ECB Working Paper No. 24, July 2000

Solow (2001), "Applying growth theory across countries", The World Bank Economic Review, v. 15 (2), pp.283-88.

Staiger D., Stock, J., and Watson, M. (1997), "How Precise are Estimates of the Natural Rate of Unemployment?", in C. Romer and D. Romer (eds), Reducing Inflation: Motivation and Strategy, University of Chicago Press.

Taylor J. B. (1999), "A Historical Analysis of Monetary Policy Rules," in Monetary Policy Rules edited by John B. Taylor (Chicago: University of Chicago Press.

Tobin J. (1997), "Supply Constraints on Employment and Output: Nairu Versus Natural Rate", Cowles Foundation Discussion Papaper n. 1150.

Quah, D., and Vahey S. (1995), "Measuring core inflation", Economic Journal, 105, $1130-1144$.

Scott, A. (2000), "A Multivariate Unobserved Components Model of Cyclical Activity", Reserve Bank of New Zealand Discussion Paper DP2000/02.

Smets, F. (1998), "Output Gap Uncertainty: Does it Matter for the Taylor Rule?", BIS Working Paper No. 60, Bank for International Settlements, Basel, Switzerland.

St-Amant, P., and van Norden, S. (1997), "Measurement of the Output Gap: A Discussion of Recent Research at the Bank of Canada", Technical Report, No. 79, Bank of Canada. 


\section{Appendix: Description of the data set}

The database is quarterly, with the sample extending from the first quarter of 1970 to the fourth quarter of 2001. As far as possible Euro area wide data were taken from official sources such as Eurostat or the European Commission. Historical data for euro area-wide aggregates were largely taken from the Area-Wide Model (AWM) database (see Fagan, Henry and Mestre, 2001, for more details on the compilation of these data, spanning the period from 1970.1 to 1998.4 for most series).

For some series, aggregates were compiled from data for the individual euro area countries using various sources, mainly the databases from the BIS, the European Commission and the OECD. Where a single source did not provide country data back to the first quarter of 1970, series from different sources were joined after having been re-based to a common base period. Moreover, where information was only available at an annual frequency (such as for working-age population), data were converted into quarterly data by means of an interpolation filter. Overall, therefore, the degree of harmonisation of the Euro area-wide data tends to be lower for the earlier parts of the sample than for the later periods.

Gross Domestic product at constant prices Seasonally adjusted. Eurostat data from 1991.1 and own compilations for previous years.

Capital stock at constant prices Constructed from Euro area wide data on seasonally adjusted fixed capital formation by means of the perpetual inventory method. Data on fixed capital formation are Eurostat data from 1991 Q1 and own compilations for previous years. Data on capital retirement constructed on the basis of a retirementto-capital ratio that gradually increases from $1.7 \%$ to $2.4 \%$ over the course of the sample. Initial capital stock reflects an investment-to-capital ratio of $7.2 \%$ at the beginning of 1970.

Employment and Unemployment Seasonally adjusted. Eurostat data from 1991.1 and AWM data for previous years.

Solow's Residual Calculated as a residual from growth accounting - real GDP minus a weighted average of the contributions from capital and employment, based on the calculation of the average labour GDP share. The latter (denoted $\alpha$ in main text) is calculated as compensation per employee times total employment over nominal GDP, averaged over the sample period.

Employment rate Seasonally adjusted. Eurostat data from 1993 Q1 and AWM data for previous years.

Working age population aged 14-65 years. Euro area wide annual data from the European Commission AMECO database interpolated to quarterly data. 
Participation rate Calculated as the ratio of the labour force over the working age population. The labour force is calculated from data on employment and unemployment.

Capacity Utilisation Seasonally adjusted rate of capacity utilisation in manufacturing. European Commission data from 1980.1 and own compilations (GDP-weighted average of available national indices) for previous years. The coverage of country data in the first half of the 1970s is somewhat less than $70 \%$ of the Euro area.

Consumer price index Not seasonally adjusted. Eurostat data from 1991.1 and own compilations for previous years.

Nominal effective exchange rate of the Euro Eurostat data from 1991.1 and own compilations for previous years.

Commodity price index (including oil) Eurostat data from 1991.1 and own compilations for previous years. 


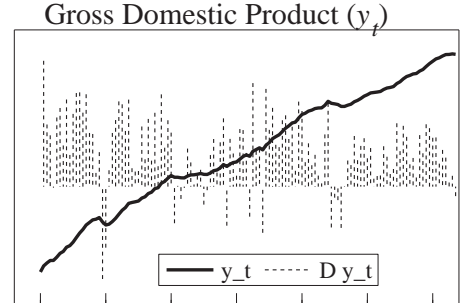

1970197519801985199019952000 Contr. Unemployment Rate

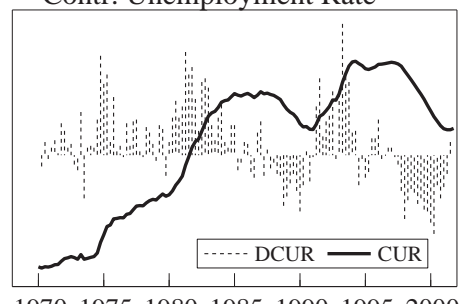

1970197519801985199019952000 Nom. Exchange Rate and Commodity Pr.

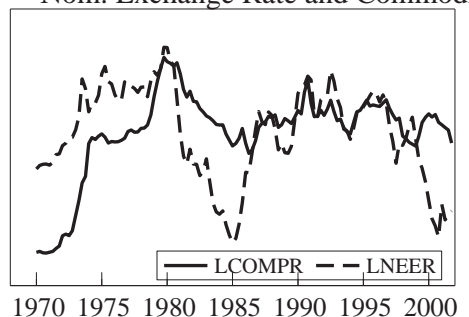

Solow's Residual $\left(f_{t}\right)$

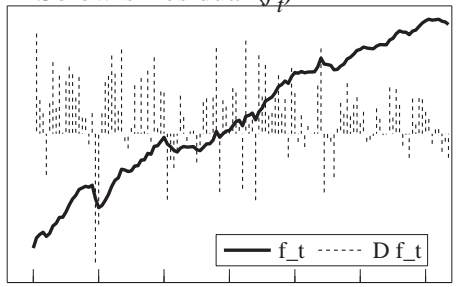

1970197519801985199019952000

Capacity Utilisation $\left(c_{t}\right)$

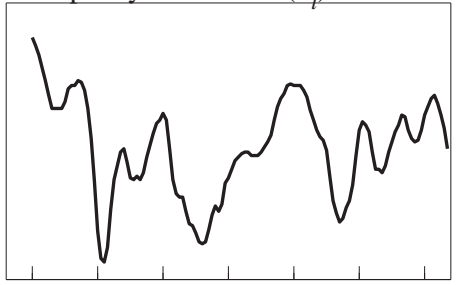

1970197519801985199019952000

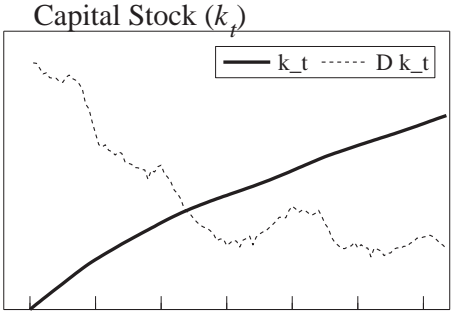

1970197519801985199019952000
Labour Force Part. Rate $([p r)$

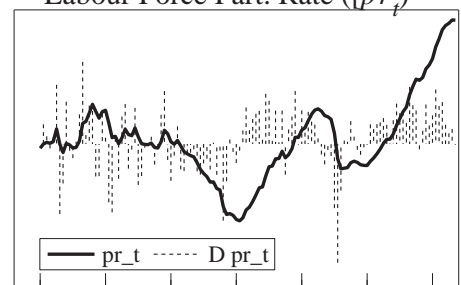

1970197519801985199019952000 Consumer Prices Index $\left(p_{t}\right)$

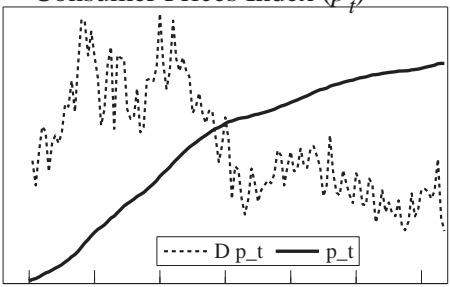

1970197519801985199019952000 Population $\left(n_{t}\right)$

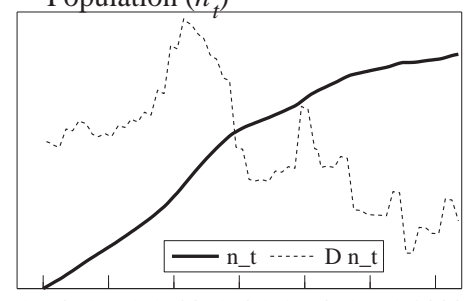

1970197519801985199019952000

Figure 1: Plot of the time series used for the implementation of the Production Function Approach.

Table 1: Parameter estimates and diagnostics for UC models of quarterly Euro Area GDP, 1970.1-2001.4. Variance parameters are multiplied by $10^{7}$; (r) denotes a restricted parameter.

\begin{tabular}{crrrrr}
\hline & Model 1 & Model 2 & Model 3 & Model 4 & Model 5 \\
& Unrestricted & $\sigma_{\zeta}^{2}=0$ & $\sigma_{\eta}^{2}=0$ & $\sigma_{\eta}^{2}=\sigma_{\epsilon}^{2}=0$ & $\mathrm{HP}$ \\
\hline$\sigma_{\eta}^{2}$ & 257.19 & 125.10 & $0(\mathrm{r})$ & $0(\mathrm{r})$ & $0(\mathrm{r})$ \\
$\sigma_{\zeta}^{2}$ & 10.81 & $0(\mathrm{r})$ & 20.63 & 15.93 & 0.98 \\
$\sigma_{\kappa}^{2}$ & 6.88 & 208.70 & 91.87 & 191.46 & 1570.10 \\
$\rho$ & 0.99 & 0.98 & 0.91 & 0.86 & $0(\mathrm{r})$ \\
$2 \pi / \lambda_{c}$ & 12.16 & 51.20 & 13.01 & 15.98 & $0(\mathrm{r})$ \\
$\sigma_{\epsilon}^{2}$ & 0.00 & 0.00 & 43.52 & $0(\mathrm{r})$ & $0(\mathrm{r})$ \\
\hline $\log$ lik & 645.08 & 639.88 & 644.01 & 643.11 & 534.86 \\
$Q(8)$ & 2.27 & 20.15 & 1.62 & 3.42 & 250.43 \\
Normality & 11.01 & 9.93 & 10.97 & 12.80 & 38.36 \\
\hline
\end{tabular}



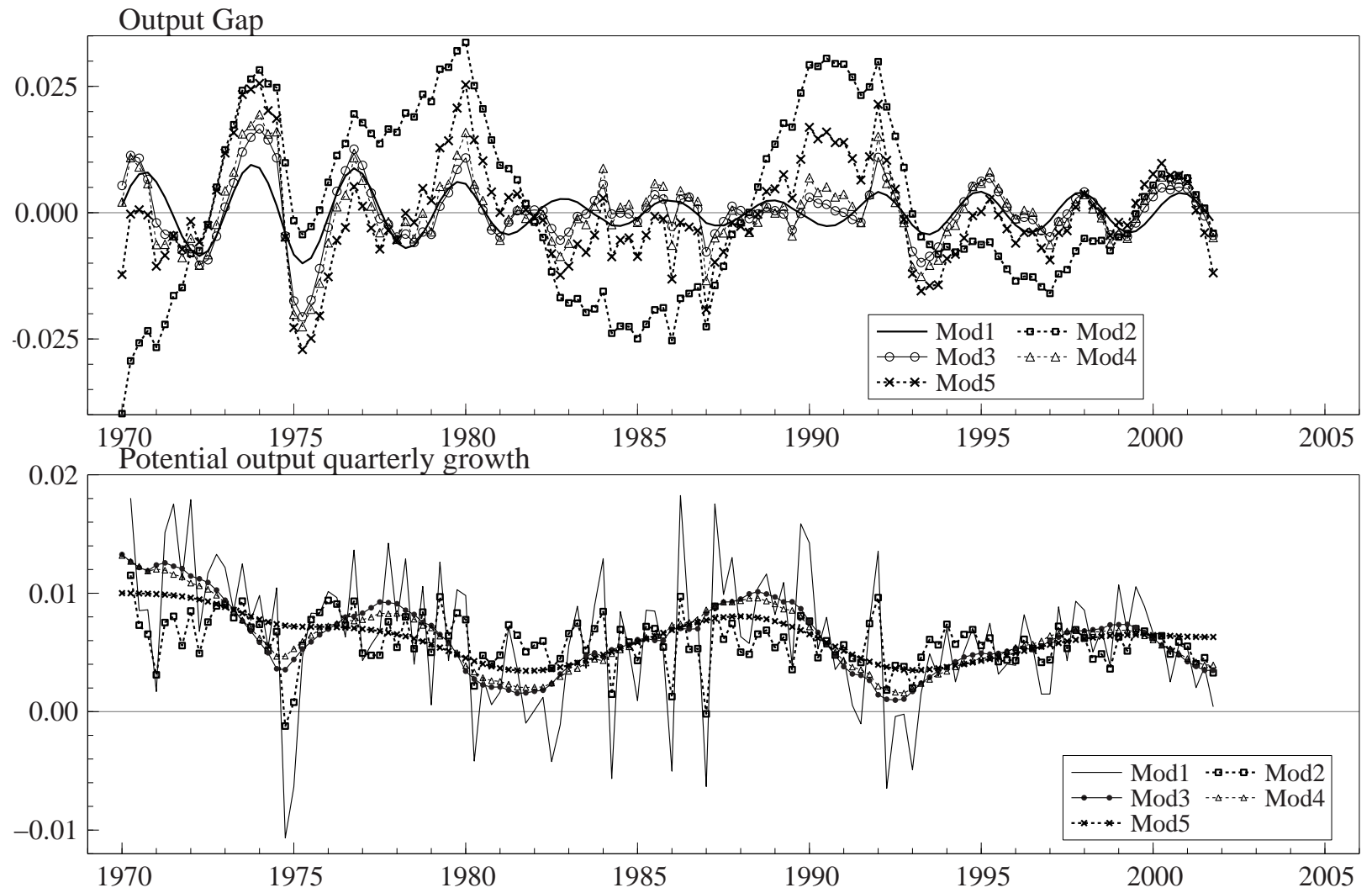

Figure 2: Univariate estimates of the output gap, $\tilde{\psi}_{t \mid T}$, and of potential output growth, $\Delta \tilde{\mu}_{t \mid T}$. 

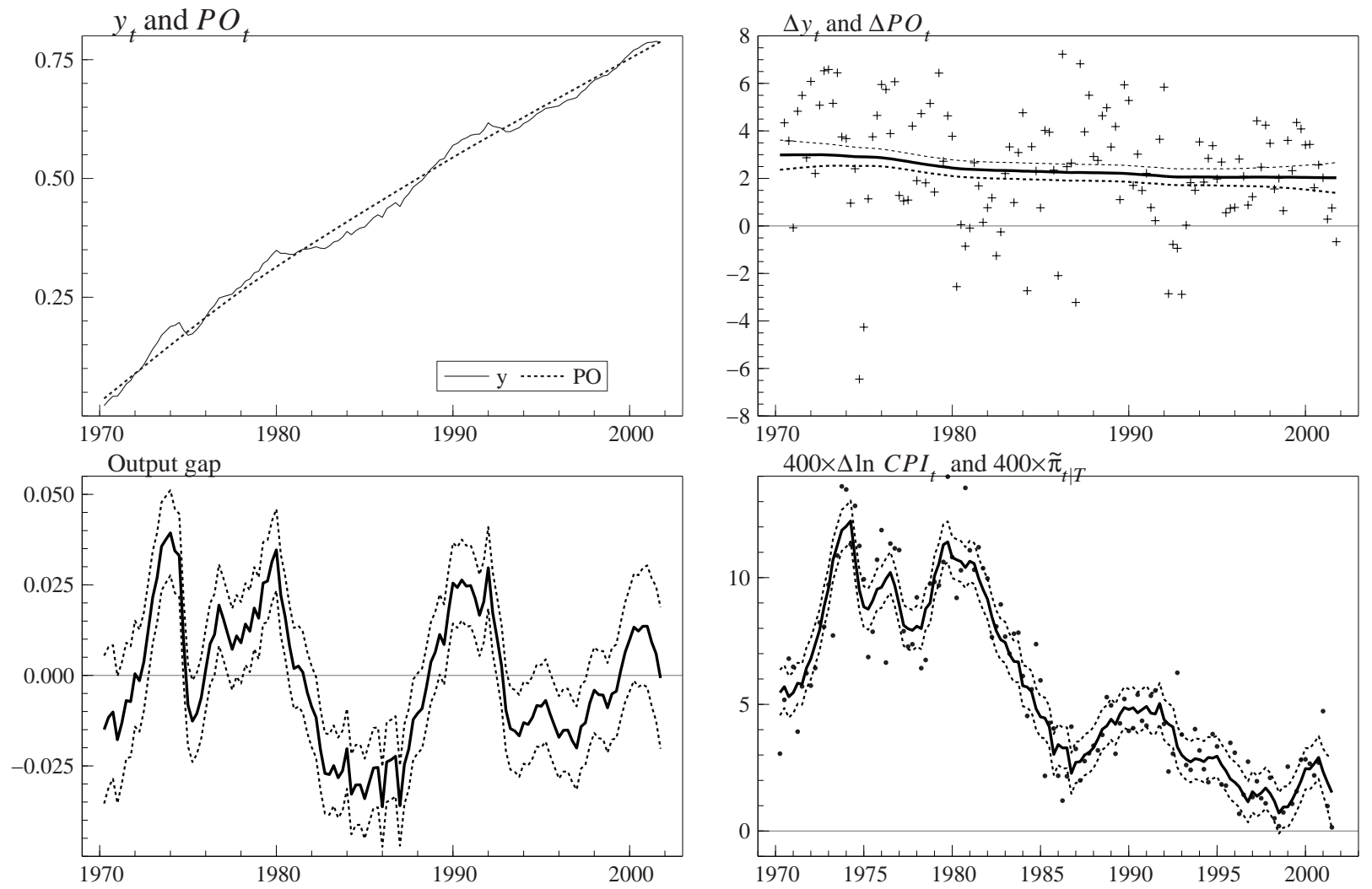

Figure 3: Bivariate estimates of potential output $\left(\tilde{\mathrm{PO}}_{t \mid T}=\tilde{\mu}_{t \mid T}\right)$, potential output growth $\left(400 \times \Delta \tilde{\mu}_{t \mid T}\right)$, the output gap $\left(\tilde{\psi}_{t \mid T}\right)$, and underlying inflation, $\left(400 \times \tilde{\pi}_{t \mid T}^{*}\right)$, with $95 \%$ confidence intervals. 

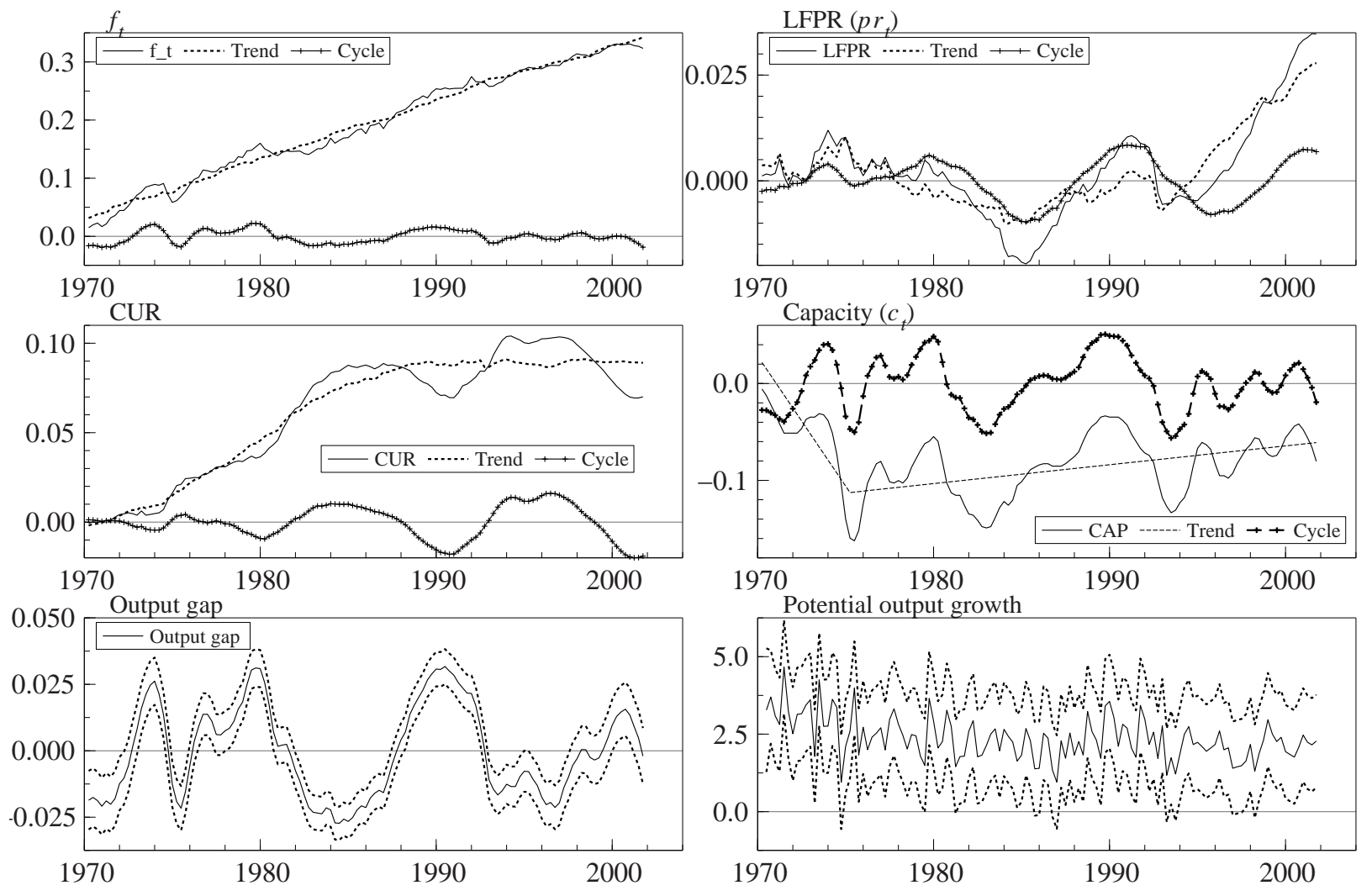

Figure 4: Multivariate Sutse model with RW trends. Smoothed components for the series and estimates of $\mathrm{OG}_{t}$ and potential output growth (with $95 \%$ confidence bounds). 

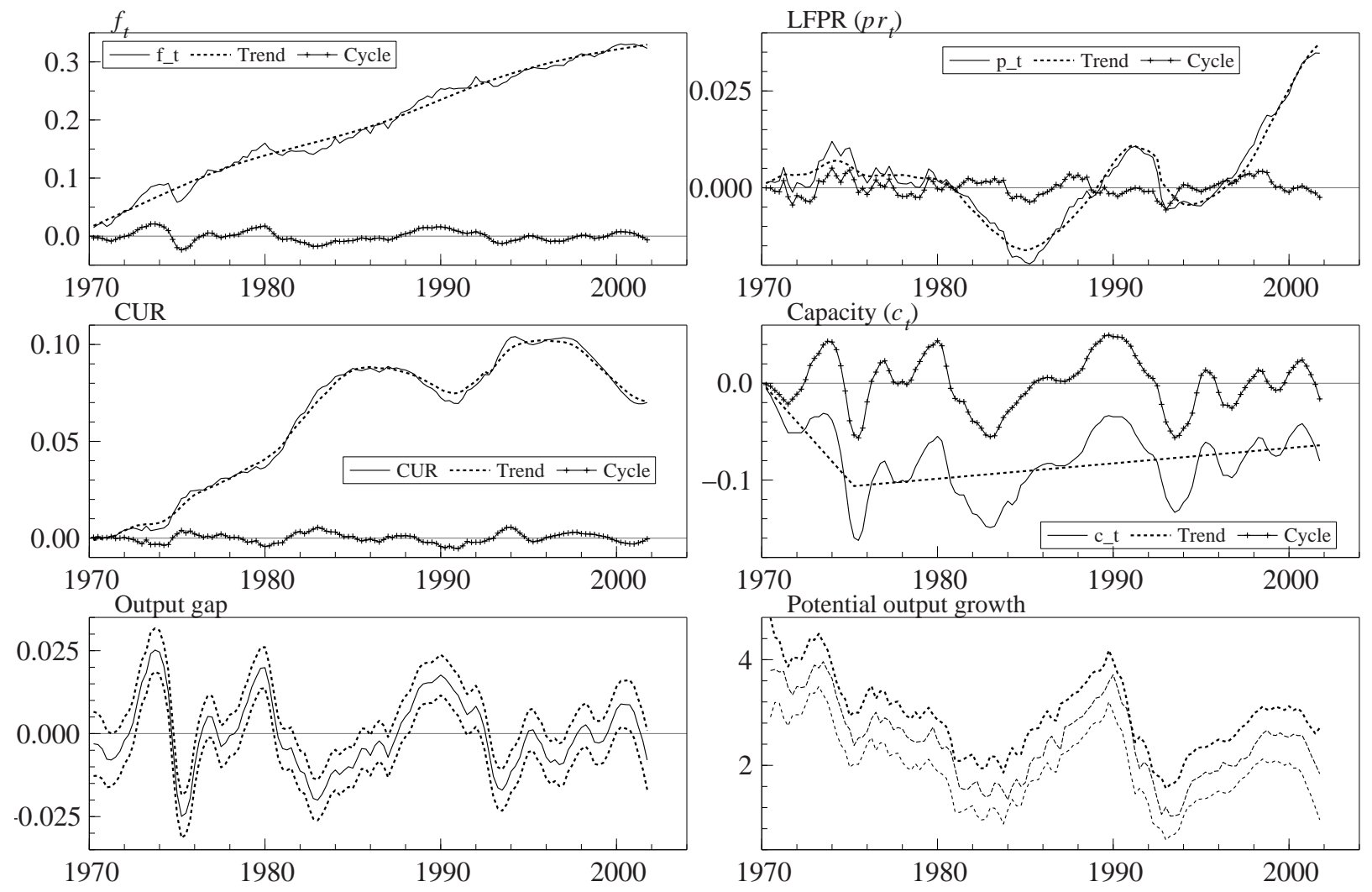

Figure 5: Multivariate Sutse model with IRW trends. Smoothed components for the series and estimates of $\mathrm{OG}_{t}$ and potential output growth (with $95 \%$ confidence bounds). 

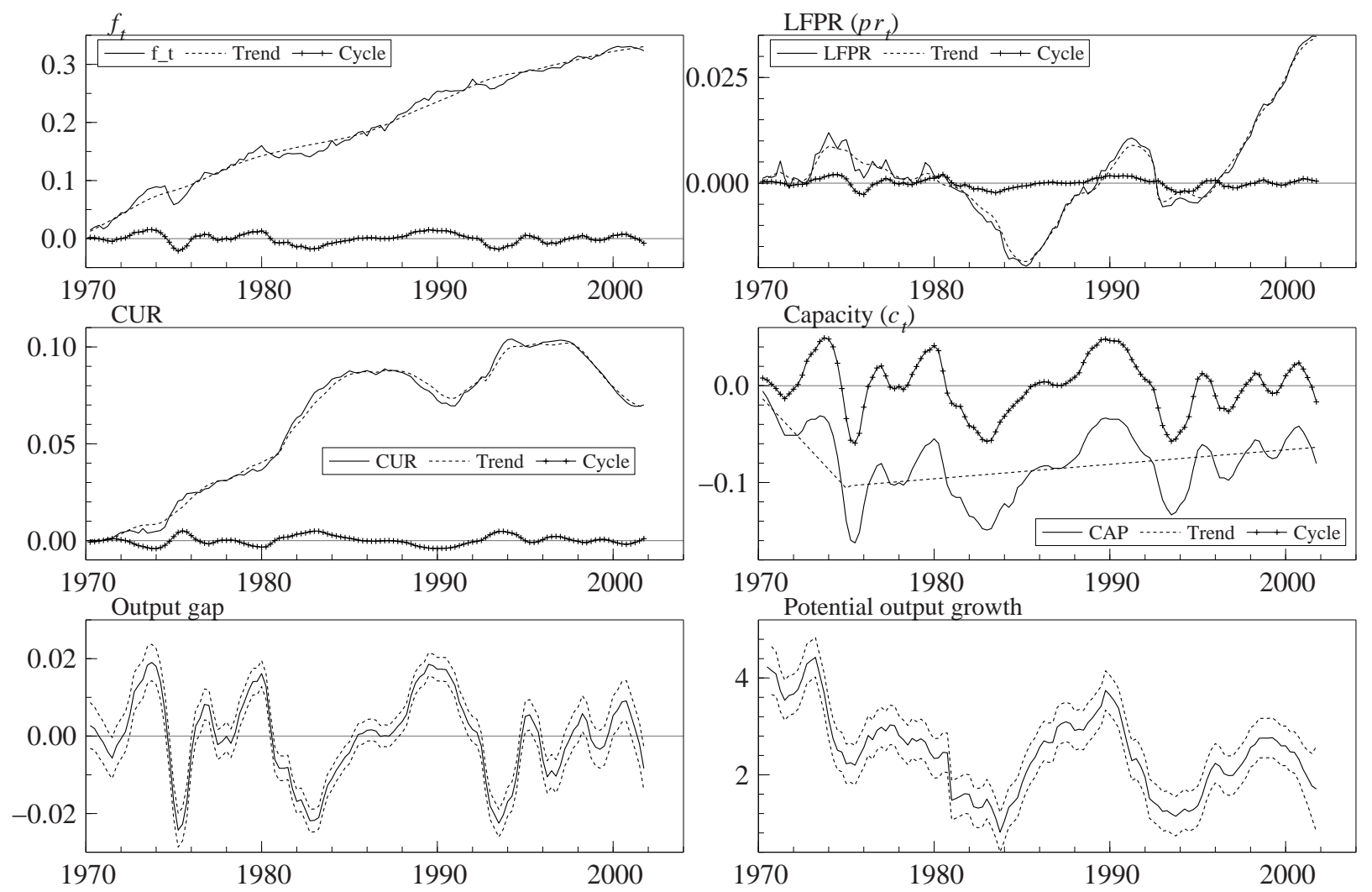

Figure 6: Multivariate Common Cycle model with IRW trends. Smoothed components for the series and estimates of $\mathrm{OG}_{t}$ and potential output growth (with $95 \%$ confidence bounds).
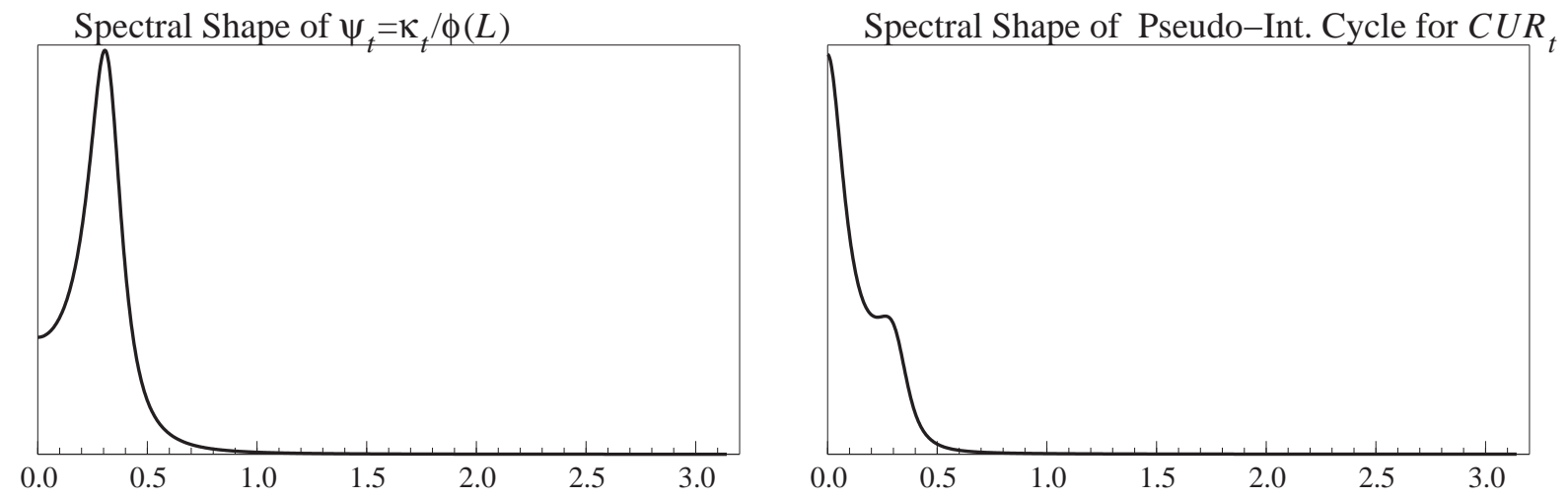

Figure 7: Typical spectral density of the process $\psi_{t}=\phi_{1} \psi_{t-1}+\phi_{2} \psi_{t-2}+\kappa_{t}$, with $\phi_{1}=1.73$ and $\phi_{2}=-0.83$ (left panel), and spectral density of the pseudo-integrated cycle $\psi_{i t}=\rho_{i} \psi_{i, t-1}+$ $\vartheta_{i}(L) \psi_{t}+\kappa_{i t}$ adapted to $\operatorname{CUR}_{t}$ (right panel). 

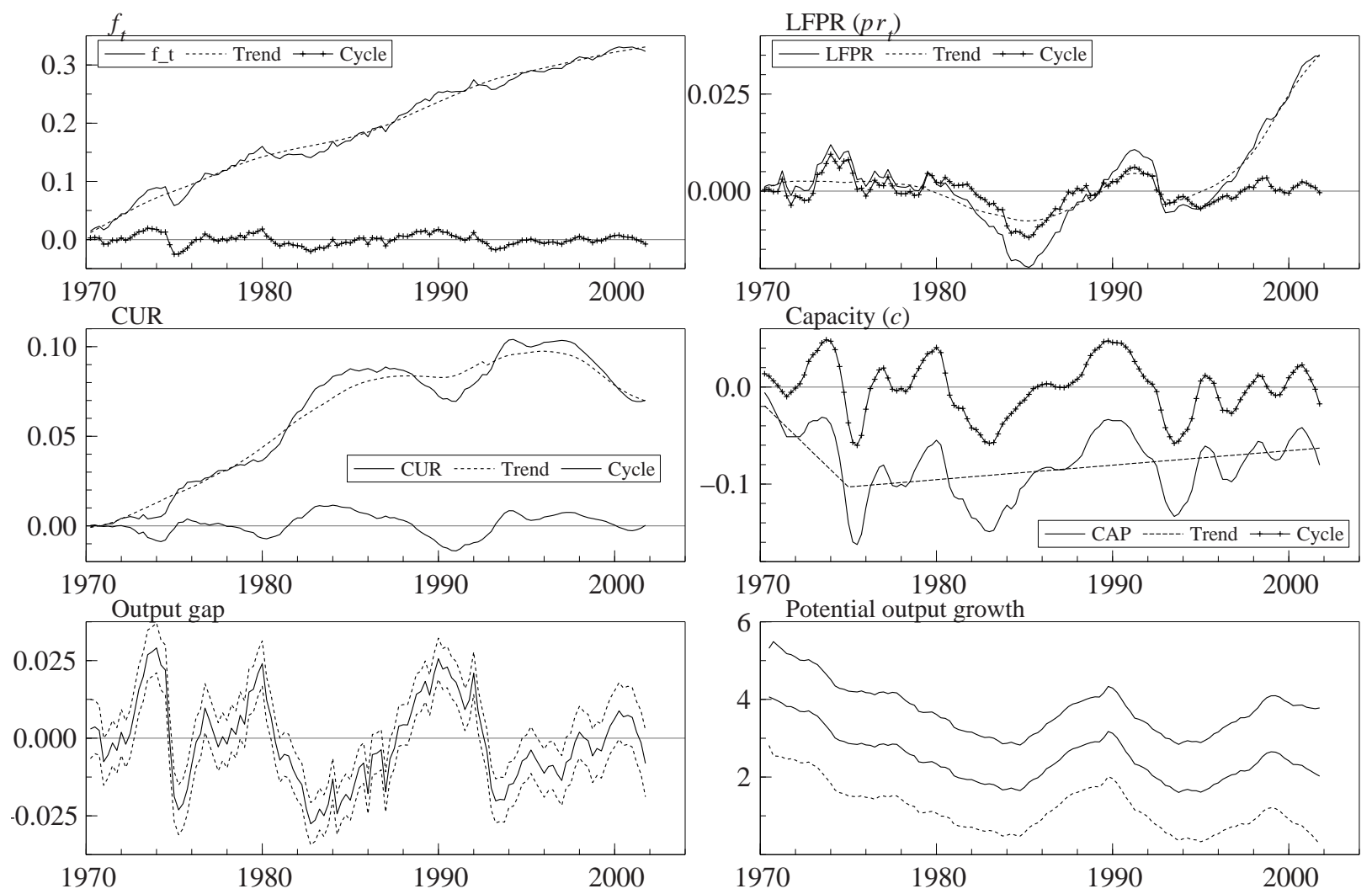

Figure 8: Multivariate PFA model with IRW trends and pseudo-integrated cycles. Smoothed components for the series and estimates of $\mathrm{OG}_{t}$ and potential output growth (with $95 \%$ confidence bounds).
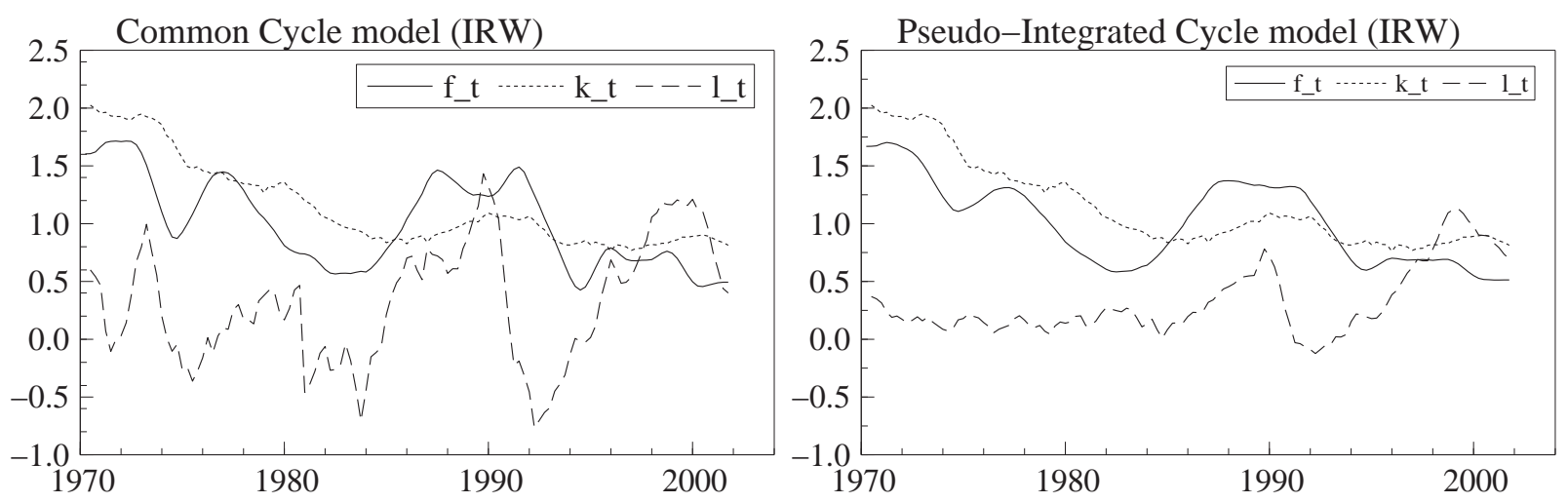

Figure 9: Growth accounting: decomposition of potential output growth into the contribution of the Solow's residual, capital and labour. 
Table 2: Parameter estimates and diagnostics for bivariate models of quarterly Euro Area log GDP $\left(y_{t}\right)$ and the logarithm of the consumer price index $\left(p_{t}\right)$, 1970.1-2001.4. Standard errors in parenthesis.

${ }^{*}$ significant at the $5 \%$ level; ${ }^{* *}$ significant at the $1 \%$ level.

\begin{tabular}{|c|c|c|c|c|c|}
\hline & Unrestricted & $\sigma_{\zeta}^{2}=0$ & Damped Slope & Coincident & $\mathrm{HP}$ \\
\hline & \multicolumn{5}{|c|}{$y_{t}$ Equation } \\
\hline$\sigma_{\eta}^{2}$ & 0.00 & 189.26 & 0.00 & - & $0(\mathrm{r})$ \\
\hline$\sigma_{\zeta}^{2}$ & 0.40 & $0(\mathrm{r})$ & 10.80 & 4.86 & 0.60 \\
\hline$\phi$ & - & - & 0.84 & - & - \\
\hline$m$ & - & - & 0.006 & - & - \\
\hline$\sigma_{\kappa}^{2}$ & 299.08 & 145.78 & 271.09 & 257.72 & 966.40 \\
\hline$\rho$ & 0.96 & 0.96 & 0.94 & 0.92 & $0(\mathrm{r})$ \\
\hline $2 \pi / \lambda_{c}$ & 46.26 & 36.44 & 36.18 & 28.84 & $0(\mathrm{r})$ \\
\hline \multirow[t]{2}{*}{$\sigma_{\epsilon}^{2}$} & 0.00 & 0.00 & 0.00 & 0.08 & $0(\mathrm{r})$ \\
\hline & \multicolumn{5}{|c|}{$p_{t}$ Equation } \\
\hline$\sigma_{\eta \pi}^{2}$ & 43.06 & 43.12 & 47.09 & 48.72 & 0.00 \\
\hline$\sigma_{\zeta \pi}^{2 \pi}$ & 11.11 & 5.24 & 5.01 & 3.98 & 9.90 \\
\hline$\sigma_{\omega}^{2}$ & 0 & 0 & 0 & 0 & 0 \\
\hline$\delta_{C 0}$ & 0.004 & 0.004 & 0.004 & 0.004 & 0.005 \\
\hline s.e & $(0.002)$ & $(0.002)$ & $(0.003)$ & $(0.002)$ & $(0.002)$ \\
\hline$\delta_{C 1}$ & 0.004 & 0.004 & 0.004 & 0.004 & 0.005 \\
\hline s.e & $(0.002)$ & $(0.002)$ & $(0.002)$ & $(0.002)$ & $(0.002)$ \\
\hline$\delta_{N 0}$ & -0.019 & -0.017 & -0.019 & -0.017 & -0.020 \\
\hline s.e & $(0.009)$ & $(0.009)$ & $(0.009)$ & $(0.009)$ & $(0.009)$ \\
\hline$\delta_{N 1}$ & -0.029 & -0.027 & -0.030 & -0.031 & -0.029 \\
\hline s.e & $(0.010)$ & $(0.009)$ & $(0.009)$ & $(0.009)$ & $(0.009)$ \\
\hline$\theta_{\pi 0}$ & 0.163 & 0.260 & 0.193 & 0.155 & 0.336 \\
\hline s.e & $(0.028)$ & $(0.063)$ & $(0.038)$ & $(0.034)$ & $(0.034)$ \\
\hline$\theta_{\pi 1}$ & -0.146 & -0.228 & -0.164 & -0.104 & -0.267 \\
\hline \multirow[t]{2}{*}{ s.e } & $(0.028)$ & $(0.057)$ & $(0.035)$ & $(0.033)$ & $(0.032)$ \\
\hline & \multicolumn{5}{|c|}{ Wald tests of restrictions } \\
\hline$\theta_{\pi}(1)=0$ & $7.27^{* *}$ & $4.11^{*}$ & $6.02^{*}$ & $14.56^{* *}$ & $10.45^{* *}$ \\
\hline$\delta_{C}(1)=0$ & $5.43^{*}$ & $5.95^{*}$ & $6.07^{*}$ & $5.97^{*}$ & $7.19^{* *}$ \\
\hline \multirow[t]{2}{*}{$\delta_{N}(1)=0$} & $13.83^{* *}$ & $11.77^{* *}$ & $15.21^{* *}$ & $15.27^{* *}$ & $13.95^{* *}$ \\
\hline & \multicolumn{5}{|c|}{ Diagnostics and goodness of fit } \\
\hline loglik & 994.10 & 990.62 & 1001.81 & 992.77 & 874.22 \\
\hline$Q(8) y_{t}$ & 9.07 & 12.11 & 6.09 & 3.96 & 261.12 \\
\hline$Q(8) p_{t}$ & 5.41 & 5.83 & 5.66 & 6.34 & 18.80 \\
\hline Normality $y_{t}$ & 8.19 & 7.01 & 5.64 & 9.74 & 16.63 \\
\hline Normality $p_{t}$ & 2.68 & 4.36 & 2.54 & 7.24 & 5.47 \\
\hline
\end{tabular}


Table 3: Univariate and bivariate models of $y_{t}$ and $p_{t}$ : comparison of forecast performance in the test period 1995.1-2001.4.

\begin{tabular}{|c|c|c|c|c|c|c|c|c|c|}
\hline \multicolumn{10}{|c|}{ Mean error in percentage points } \\
\hline & \multicolumn{9}{|c|}{ Forecast lead time } \\
\hline Models & $1 \mathrm{qrt}$ & 2 qrts & 3 qrts & 4 qrts & 5 qrts & 6 qrts & 7 qrts & 8 qrts & 12 qrts \\
\hline RWSD & -0.01 & 0.05 & 0.01 & -0.02 & -0.19 & -0.35 & -0.63 & -0.64 & -1.09 \\
\hline Univariate & -0.01 & 0.03 & -0.01 & -0.10 & -0.27 & -0.46 & -0.68 & -0.76 & -1.16 \\
\hline Bivariate Unrestricted & -0.01 & 0.02 & -0.04 & -0.14 & -0.26 & -0.44 & -0.65 & -0.71 & -1.14 \\
\hline Bivariate $\sigma_{\zeta}^{2}=0$ & -0.01 & 0.02 & -0.06 & -0.19 & -0.38 & -0.63 & -0.95 & -1.09 & -1.94 \\
\hline Biv. Damped Slope & -0.00 & 0.04 & -0.00 & -0.11 & -0.27 & -0.49 & -0.75 & -0.87 & -1.52 \\
\hline Biv. Coincident & -0.05 & -0.07 & -0.20 & -0.41 & -0.65 & -0.94 & -1.25 & -1.40 & -2.13 \\
\hline Biv. HP & -0.06 & -0.04 & -0.11 & -0.26 & -0.41 & -0.62 & -0.84 & -0.94 & -1.39 \\
\hline \multicolumn{10}{|c|}{ Relative root mean square error } \\
\hline & \multicolumn{9}{|c|}{ Forecast lead time } \\
\hline Models & $1 \mathrm{qrt}$ & 2 qrts & 3 qrts & 4 qrts & 5 qrts & 6 qrts & 7 qrts & 8 qrts & 12 qrts \\
\hline RWSD & 1.00 & 1.00 & 1.00 & 1.00 & 1.00 & 1.00 & 1.00 & 1.00 & 1.00 \\
\hline Univariate & 0.90 & 0.82 & 0.81 & 0.80 & 0.80 & 0.78 & 0.84 & 0.89 & 1.01 \\
\hline Bivariate Unrestricted & 0.83 & 0.69 & 0.62 & 0.60 & 0.70 & 0.75 & 0.88 & 0.90 & 1.02 \\
\hline Bivariate $\sigma_{\zeta}^{2}=0$ & 0.84 & 0.71 & 0.66 & 0.67 & 0.82 & 0.92 & 1.13 & 1.24 & 1.70 \\
\hline Biv. Damped Slope & 0.83 & 0.70 & 0.65 & 0.63 & 0.74 & 0.80 & 0.96 & 1.03 & 1.34 \\
\hline Biv. Coincident & 0.90 & 0.81 & 0.85 & 0.91 & 1.08 & 1.17 & 1.41 & 1.54 & 1.87 \\
\hline Biv. HP & 0.84 & 0.80 & 0.81 & 0.80 & 0.86 & 0.86 & 0.98 & 1.06 & 1.21 \\
\hline Root MSE RWSD & 0.02 & 0.03 & 0.03 & 0.04 & 0.04 & 0.04 & 0.04 & 0.04 & 0.03 \\
\hline
\end{tabular}

Table 4: Likelihood and Ljung-Box statistics for multivariate SUTSE models

\begin{tabular}{lrrr}
\hline & RW & IRW & DSlope \\
\hline \multicolumn{4}{c}{ Log Likelihood } \\
& 2702.11 & 2749.71 & 2778.23 \\
\hline \multicolumn{4}{c}{ Ljung-Box Statistic, $Q(8)$} \\
$f_{t}$ & 22.42 & 14.29 & 12.99 \\
$p r_{t}$ & 16.00 & 9.14 & 8.78 \\
CUR $_{t}$ & 93.91 & 17.62 & 16.21 \\
$c_{t}$ & 153.79 & 101.34 & 97.63 \\
$\ln \mathrm{CPI}$ & 7.41 & 8.05 & 7.46 \\
\hline
\end{tabular}


Table 5: Parameter estimates and diagnostics for multivariate common cycle models

\begin{tabular}{|l|rrr|rrrr|}
\hline & \multicolumn{3}{|c|}{ IRW } & \multicolumn{4}{c|}{ DSlope } \\
\hline Log Lik. & \multicolumn{3}{|c|}{2805.77} & \multicolumn{4}{c|}{2833.20} \\
\hline \multirow{3}{*}{$f_{t}$} & $\tilde{\theta}_{i 0}$ & $\tilde{\theta}_{i 1}$ & $Q(8)$ & $\tilde{\theta}_{i 0}$ & $\tilde{\theta}_{i 1}$ & Slope & $Q(8)$ \\
\cline { 2 - 8 }$p r_{t}$ & $0.50^{*}$ & $-0.20^{*}$ & 16.43 & $0.49^{*}$ & $-0.19^{*}$ & 0.00 & 10.96 \\
CUR $_{t}$ & -0.04 & $0.07^{*}$ & 9.92 & -0.04 & $0.07^{*}$ & $0.76^{*}$ & 3.67 \\
$c_{t}$ & $-0.06^{*}$ & -0.03 & 13.62 & $-0.06^{*}$ & -0.03 & $0.88^{*}$ & 12.68 \\
$p_{t}$ & 1 & - & 15.06 & 1 & - & - & 15.32 \\
\cline { 2 - 8 } & $0.19^{*}$ & $-0.14^{*}$ & 5.12 & $0.19^{*}$ & $-0.14^{*}$ & - & 5.16 \\
\hline
\end{tabular}

Table 6: Parameter estimates and diagnostics for multivariate hysteresis models

\begin{tabular}{|c|c|c|c|c|c|c|c|c|c|c|c|}
\hline & \multicolumn{5}{|c|}{$\mathrm{I}(2)$} & \multicolumn{6}{|c|}{ DSlope } \\
\hline Log Lik. & \multicolumn{5}{|c|}{2780.71} & \multicolumn{6}{|c|}{2820.69} \\
\hline & $\tilde{\vartheta}_{i 0}$ & $\tilde{\vartheta}_{i 1}$ & $\tilde{\vartheta}_{i 2}$ & $\tilde{\vartheta}_{i}(1)$ & $Q(8)$ & $\tilde{\vartheta}_{i 0}$ & $\tilde{\vartheta}_{i 1}$ & $\tilde{\vartheta}_{i 2}$ & $\tilde{\vartheta}_{i}(1)$ & Slope & $Q(8)$ \\
\hline$f_{t}$ & $0.55^{*}$ & $-0.79^{*}$ & $0.25^{*}$ & 0.01 & 17.24 & $0.55^{*}$ & $-0.79^{*}$ & $0.26^{*}$ & 0.02 & 0.00 & 11.22 \\
\hline$p r_{t}$ & -0.04 & $0.13^{*}$ & $-0.08^{*}$ & 0.01 & 23.33 & -0.02 & $0.11^{*}$ & $-0.07^{*}$ & $0.02^{*}$ & $0.27^{*}$ & 10.09 \\
\hline $\mathrm{CUR}_{t}$ & $-0.11^{*}$ & $0.11^{*}$ & $-0.03^{*}$ & $-0.03^{*}$ & 15.39 & $-0.10^{*}$ & $0.10^{*}$ & $-0.02^{*}$ & $-0.02^{*}$ & $0.90^{*}$ & 15.06 \\
\hline$c_{t}$ & 1 & - & - & - & 15.10 & 1 & - & - & - & - & 15.32 \\
\hline$p_{t}$ & $0.16^{*}$ & $-0.12^{*}$ & - & - & 6.75 & $0.16^{*}$ & $-0.12^{*}$ & - & - & - & 5.16 \\
\hline
\end{tabular}

Table 7: Parameter estimates and diagnostics for multivariate PFA models with pseudointegrated cycles

\begin{tabular}{|l|rrrrr|rrrrrr|}
\hline & \multicolumn{9}{|c|}{ IRW } & \multicolumn{6}{c|}{ DSlope } \\
\hline Log Lik. & \multicolumn{4}{|c|}{2816.79} & \multicolumn{5}{c|}{2828.23} \\
\hline \multirow{3}{*}{$f_{t}$} & $\tilde{\theta}_{i 0}$ & $\tilde{\theta}_{i 1}$ & $\tilde{\rho}_{i}$ & $\tilde{\sigma}_{\kappa, i}$ & $Q(8)$ & $\tilde{\theta}_{i 0}$ & $\tilde{\theta}_{i 1}$ & $\tilde{\rho}_{i}$ & $\tilde{\sigma}_{\kappa, i}$ & Slope & $Q(8)$ \\
\cline { 2 - 12 } & $0.42^{*}$ & $-0.23^{*}$ & $0.34^{*}$ & 134 & 5.60 & $0.44^{*}$ & $-0.21^{*}$ & $0.21^{*}$ & 0 & 0.00 & 9.77 \\
CUR $_{t}$ & $0.02^{*}$ & $0.01^{*}$ & $0.89^{*}$ & 7 & 10.42 & 0.01 & $0.01^{*}$ & $0.90^{*}$ & 0 & $0.99^{*}$ & 9.98 \\
$c_{t}$ & $-0.08^{*}$ & $0.04^{*}$ & $0.91^{*}$ & 7 & 12.12 & $-0.08^{*}$ & $0.04^{*}$ & $0.92^{*}$ & 8 & $0.98^{*}$ & 13.09 \\
$p_{t}$ & 1 & - & - & - & 15.10 & 1 & - & - & - & - & 16.36 \\
& $0.04^{*}$ & $-0.02^{*}$ & - & - & 6.75 & $0.04^{*}$ & $-0.03^{*}$ & - & - & - & 6.64 \\
\hline
\end{tabular}




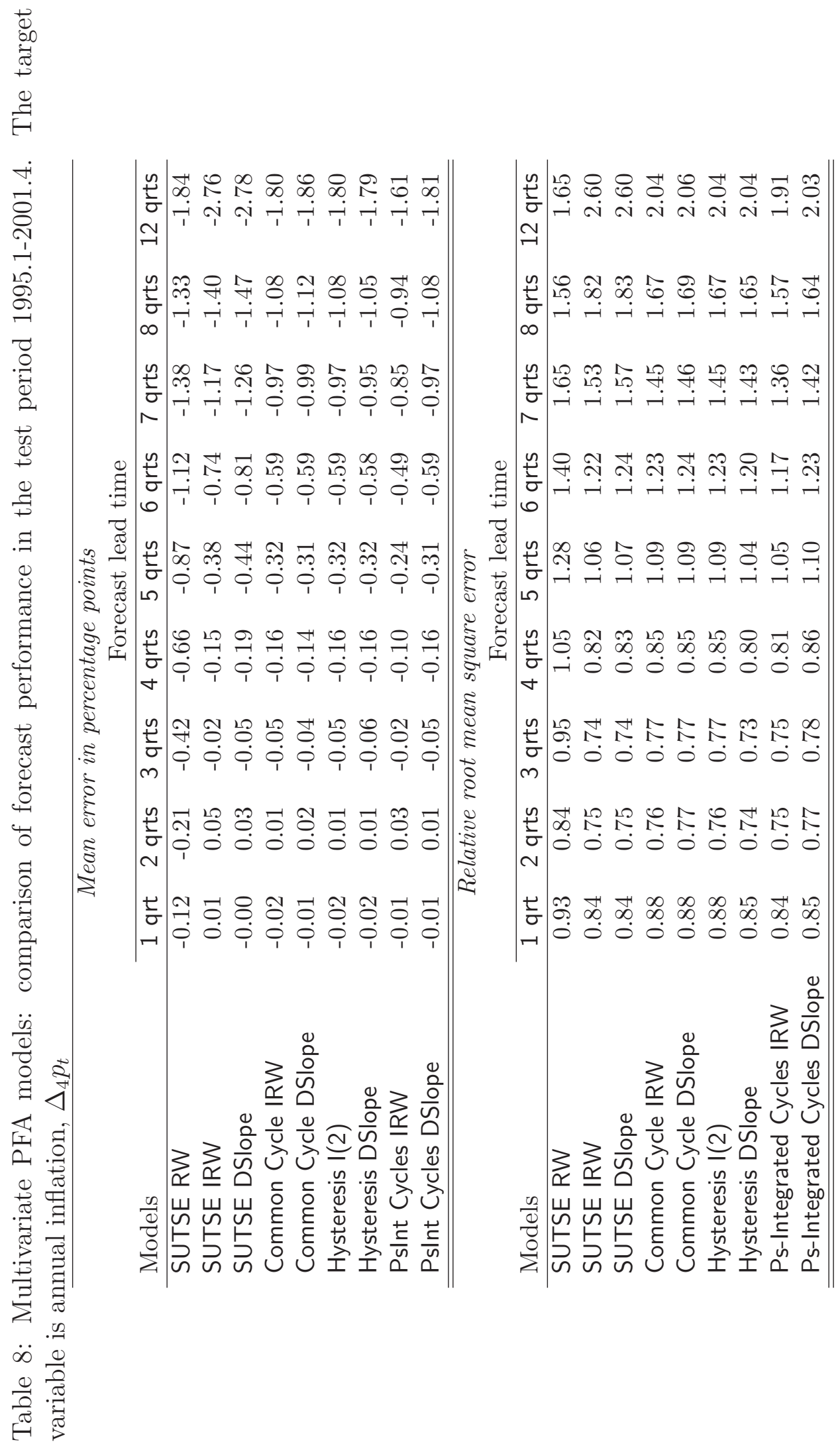

